University of South Carolina

Scholar Commons

$1-1-2005$

\title{
The Effects of Satellite-Derived Vegetation Cover Variability on Simulated Land-Atmosphere Interactions in the NAMS
}

\author{
Toshi Matsui \\ University of South Carolina - Columbia \\ Venkataraman Lakshmi \\ University of South Carolina - Columbia, vlakshmi@geol.sc.edu \\ Eric Small
}

Follow this and additional works at: https://scholarcommons.sc.edu/geol_facpub

Part of the Earth Sciences Commons

\section{Publication Info}

Published in Journal of Climate, Volume 18, 2005, pages 21-40.

Matsui, T., Lakshmi, V., \& Small, E. E. (2005). The effects of satellite-derived vegetation cover variability on simulated land-atmosphere interactions in the NAMS. Journal of Climate, 18, 21-40.

(c) Copyright 2005 AMS

This Article is brought to you by the Earth, Ocean and Environment, School of the at Scholar Commons. It has been accepted for inclusion in Faculty Publications by an authorized administrator of Scholar Commons. For more information, please contact digres@mailbox.sc.edu. 


\title{
The Effects of Satellite-Derived Vegetation Cover Variability on Simulated Land-Atmosphere Interactions in the NAMS
}

\author{
TOSHIHISA Matsui* AND Venkataraman LaKshmi \\ Department of Geological Sciences, University of South Carolina, Columbia, South Carolina \\ ERIC E. SMALL \\ Department of Geological Sciences, University of Colorado, Boulder, Colorado
}

(Manuscript received 26 March 2003, in final form 10 November 2003)

\begin{abstract}
Substantial evolution of Normalized Difference Vegetation Index (NVDI)-derived vegetation cover (Fg) exists in the southwestern United States and Mexico. The intraseasonal and wet-/dry-year fluctuations of Fg are linked to observed precipitation in the North American monsoon system (NAMS). The manner in which the spatial and temporal variability of $\mathrm{Fg}$ influences the land-atmosphere energy and moisture fluxes, and associated likelihood of moist convection in the NAMS regions, is examined. For this, the regional climate model (RCM) is employed, with three different Fg boundary conditions to examine the influence of intraseasonal and wet-/dry-year vegetation variability. Results show that a strong link exists between evaporative fraction (EF), surface temperature, and relative humidity in the boundary layer (BL), which is consistent with a positive soil moisture feedback. However, contrary to expectations, higher Fg does not consistently enhance EF across the NAMS region. This is because the low soil moisture values simulated by the land surface model (LSM) yield high canopy resistance values throughout the monsoon season. As a result, the experiment with the lowest Fg yields the greatest EF and precipitation in the NAMS region, and also modulates regional atmospheric circulation that steers the track of tropical cyclones. In conclusion, the simulated influence of vegetation on land-atmosphere exchanges depends strongly on the canopy stress index parameterized in the LSM. Therefore, a reliable dataset, at appropriate scales, is needed to calibrate transpiration schemes and to assess simulated and realistic vegetation-atmosphere interactions in the NAMS region.
\end{abstract}

\section{Introduction}

The North American monsoon system (NAMS) is characterized by the seasonal shifts of pressure and wind patterns and the associated large amount of summertime rainfall over the southwest United States and the Sierra Madre Occidental in Mexico (referred to as the NAMS region in this paper) (Adams and Comrie 1997; Higgins et al. 1997). The onset of the North American monsoon (NAM) is typically abrupt and occurs in June or early July, depending upon location. Year-to-year fluctuations of the NAMS are also substantial, affecting the summertime precipitation regime

\footnotetext{
* Current affiliation: Department of Atmospheric Science, Colorado State University, Fort Collins, Colorado.
}

Corresponding author address: Dr. Venkataraman Lakshmi, Department of Geological Sciences, University of South Carolina, 701 Sumpter Street, Columbia, SC 29223.

E-mail: venkat-lakshmi@sc.edu in North America (Higgins et al. 1997). Accurate predictions of the NAMS variability could mitigate natural hazards, such as severe flood or drought (Trenberth and Branstator 1996). These predictions require identifying the driving force of the NAMS.

While sea surface temperature (SST) and associated global atmospheric circulation pattern predominantly control the NAMS variability (Higgins et al. 1999; Castro et al. 2001), land surface conditions may also influence the NAMS variability (Gutzler and Preston 1997; Small 2001; Lo and Martyn 2002). Springtime snowpack over the southern Rocky Mountains (SRM) is proposed to modulate the pressure gradient between the ocean and continent interior via the changing surface albedo and subsequent soil moisture anomalies (Gutzler and Preston 1997). Yet the influence of land surface anomalies could be masked by the influence of SST or associated large-scale atmospheric circulation pattern; therefore, it may be difficult to find statistically significant relationships using only observed data (Matsui et al. 2003).

A limited-area regional climate model (RCM) can be 
used to physically study the importance of complex landatmosphere interactions (Giorgi and Mearns 1999). The climate of the NAMS region is unique: land surface conditions, sea breezes, orographic lifting, and largescale monsoon circulation may affect the rainfall pattern (Adams and Comrie 1997). Small (2001) used the fifth-generation Pennsylvania State University (PSU)National Center for Atmospheric Research (NCAR) Mesoscale Model (MM5)-Oregon State University (OSU) Land Surface Model (LSM) to examine the sensitivity of the NAM simulations to the soil moisture anomalies in the different regions, and found that soil moisture held at field capacity throughout the NAMS region enhances precipitation over the NAMS. In contrast, soil moisture consistently at field capacity over the SRM suppresses the NAMS precipitation, consistent with the hypothesis proposed by Gutzler and Preston (1997). This result motivated our further investigations of the influence of land surface interactions in the NAMS.

Throughout the NAMS region, intraseasonal and wet-/dry-year fluctuations in precipitation cause significant variability in the status of vegetation (Swetnam and Betancourt 1998). Variability of vegetation can modulate the surface energy budget and the partitioning of available energy into sensible and latent heat fluxes via the closing/opening of stomata, ground fractional coverage, leaf area index (LAI), and vegetation types (e.g., Sud et al. 1993; Eastman et al. 2001). Vegetation may decrease the runoff ratio by temporarily holding rain droplets on the canopy and absorbing soil water from the root zone. Thus, vegetation can enhance the soil moisture recycling ration, which can contribute local moisture convergence to increase precipitation (e.g., Bosilovich and Schubert 2002). Also, increased transpiration (latent heat flux) yields a higher evaporative fraction (EF; defined as latent heat flux divided by the available energy), which can lead to unstable vertical profiles of temperature and moisture, which likely trigger moist convection (e.g., Betts and Ball 1998). Alternatively, lower EF induces a sea breeze to permit a greater likelihood of moist convection (e.g., Segal et al. 1988). Based on an extensive review, Pielke (2001) concluded that the spatial patterning of deep cumulus convection, particularly in the Tropics and midlatitude summers, are altered significantly as a result of landscape change.

This paper provides an analysis of variability of Normalized Difference Vegetation Index (NDVI)-derived vegetation cover and its influence on the NAM simulations during June-September 2000. First, statistical analyses are used to characterize temporal and spatial vegetation variability and its relationship to the seasonal and wet-/dry-year NAM precipitation. Second, a RCM is used to investigate the feedback of vegetation to the atmosphere through incorporating different NDVI-derived vegetation boundary conditions in order to modulate surface albedo and the surface energy par- titioning. Our goals are to assess (a) whether or not the vegetation feedback exists, and (b) if the feedback exists, whether the feedback is negative or positive. Because the mechanism of summer precipitation is essentially of the convective type, we hypothesize the variability of vegetation cover to be a strong modulator for patterning of the moist convection in conjunction with the change in the surface energy flux and boundary layer (BL) conditions (Betts and Ball 1998; Eltahir 1998).

Section 2 shows the derivation of the vegetation parameter (2a), a comparison to a different dataset (2b), and the observed precipitation (2c). Section 3 describes the model and simulation setup, such as parameterization scheme, domain and grid size, and various input datasets. Section $3 \mathrm{~b}$ examines the results by validating them with the observed precipitation $[3 b(1)]$, analyzing the vegetation feedback at the regional scale $[3 b(2)]$ and local (grid) scale [3b(3)], examining the canopy resistance parameterization described in the appendix to analyze the influence of soil moisture and soil texture types [section $3 b(4)$ ], and examining the modulation of regional atmospheric circulation [section $3 b(5)]$. Section 4 summarizes the experiment and hypothesis test and section 5 discusses the uncertainties and future improvement.

\section{Analysis of greenness fraction in the NAMS region}

\section{a. Derivation of greenness fraction}

The Fg parameter is defined as a sub-grid horizontal fraction of dense green vegetation. We derived Fg from a monthly composite of a grid-based Global Inventory Monitoring and Modeling Studies (GIMMS) (see information online at http://tpwww.gsfc.nasa.gov/gimms/ htdocs/). A major difficulty in deriving Fg is due to the nature of three-dimensional structure of the NDVI; that is, NDVI is composed of a vertical component (LAI) and a horizontal component (Fg) (Price 1993). Either Fg or LAI must be prescribed in order to derive the other. For example, LAI is derived from NDVI under the assumption that each grid cell holds $100 \%$ of Fg through the season (Sellers et al. 1996), whereas Fg is derived under the assumption of seasonally fixed LAI (Gutman and Ignatov 1998). Hence, incorporation of both the LAI and the Fg could double count the variability of the NDVI. Although the Fg and LAI are equally important vegetation parameters, the natural variability in $\mathrm{Fg}$ seems substantially higher due to the linear linkage to the NDVI. Therefore, the wet-/dryyear and seasonal Fg are assembled to represent vegetation variability in the current OSU LSM (Chen and Dudhia 2001a).

Gutman and Ignatov (1998) justified the method to prescribe LAI and derive Fg from the global vegetation index (GVI) climatology. We employ the procedure 
similar to that of Gutman and Ignatov (1998). First, the historical maximum NDVI (NDVI ${ }_{\max }$ ) and the historical minimum NDVI $\left(\mathrm{NDVI}_{\min }\right)$ are derived from the 20-yr monthly GIMMS NDVI at each grid point. The derived $\mathrm{NDVI}_{\max }$ and $\mathrm{NDVI}_{\max }-\mathrm{NDVI}_{\min }$ are overlaid to cluster the biome into highly seasonal, evergreen, and arid regions, using the Iterative SelfOrganizing Data Analysis Technique (ISODATA; ERDAS 1994). This land cover categorization is similar to, but independent from, the United States Geological Survey (USGS) land cover data used to specify the cover type for each grid cell. NDVI with $100 \%$ of $\mathrm{Fg}$ $\left(\mathrm{NDVI}_{\mathrm{Fg} 100}\right)$ is prescribed from the highest $3 \%$ population of $\mathrm{NDVI}_{\max }$ for the highly seasonal (0.74) and evergreen (0.67) regions, because it is likely that these ecosystems reach an Fg of $100 \%$ (Sellers et al. 1996). $\mathrm{NDVI}_{\mathrm{Fg} 100}$ is prescribed at 0.52 for the arid region (Gutman and Ignatov 1998). Similarly, NDVI with $0 \%$ $\mathrm{Fg}\left(\mathrm{NDVI}_{\mathrm{Fg} 0}\right)$ is prescribed from the lowest $3 \%$ popu- lation of $\mathrm{NDVI}_{\min }$ for the highly seasonal (0.04) and desert (0.05) regions, because it is most likely that these ecosystems have $0 \% \mathrm{Fg}$. Because the evergreen region, literally, cannot have $0 \% \mathrm{Fg}, \mathrm{NDVI}_{\mathrm{Fg} 0}$ is assigned at 0.03 . Thereby, the $20-\mathrm{yr}$ monthly $\mathrm{Fg}$ is computed for highly seasonal, evergreen, and arid areas separately from the GIMMS NDVI:

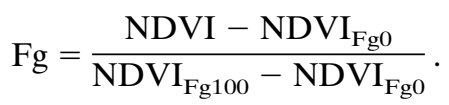

\section{b. Comparison between different greenness fraction datasets}

We compare the GIMMS NDVI-derived Fg in wetyear $2000\left(\mathrm{Fg}_{2000}\right)$ and the Fg climatology from Gutman and Ignatov (1998) $\left(\mathrm{Fg}_{\mathrm{GI}}\right)$. Figure 1 depicts latitudinal profiles of monthly Fg from May to August, ranging from the south $\left(22.1^{\circ} \mathrm{N}, 105.5^{\circ} \mathrm{W}\right)$ to the north $\left(33.5^{\circ} \mathrm{N}\right.$, $105.5^{\circ} \mathrm{W}$ ) across the NAMS regions (Fig. 2). Notable
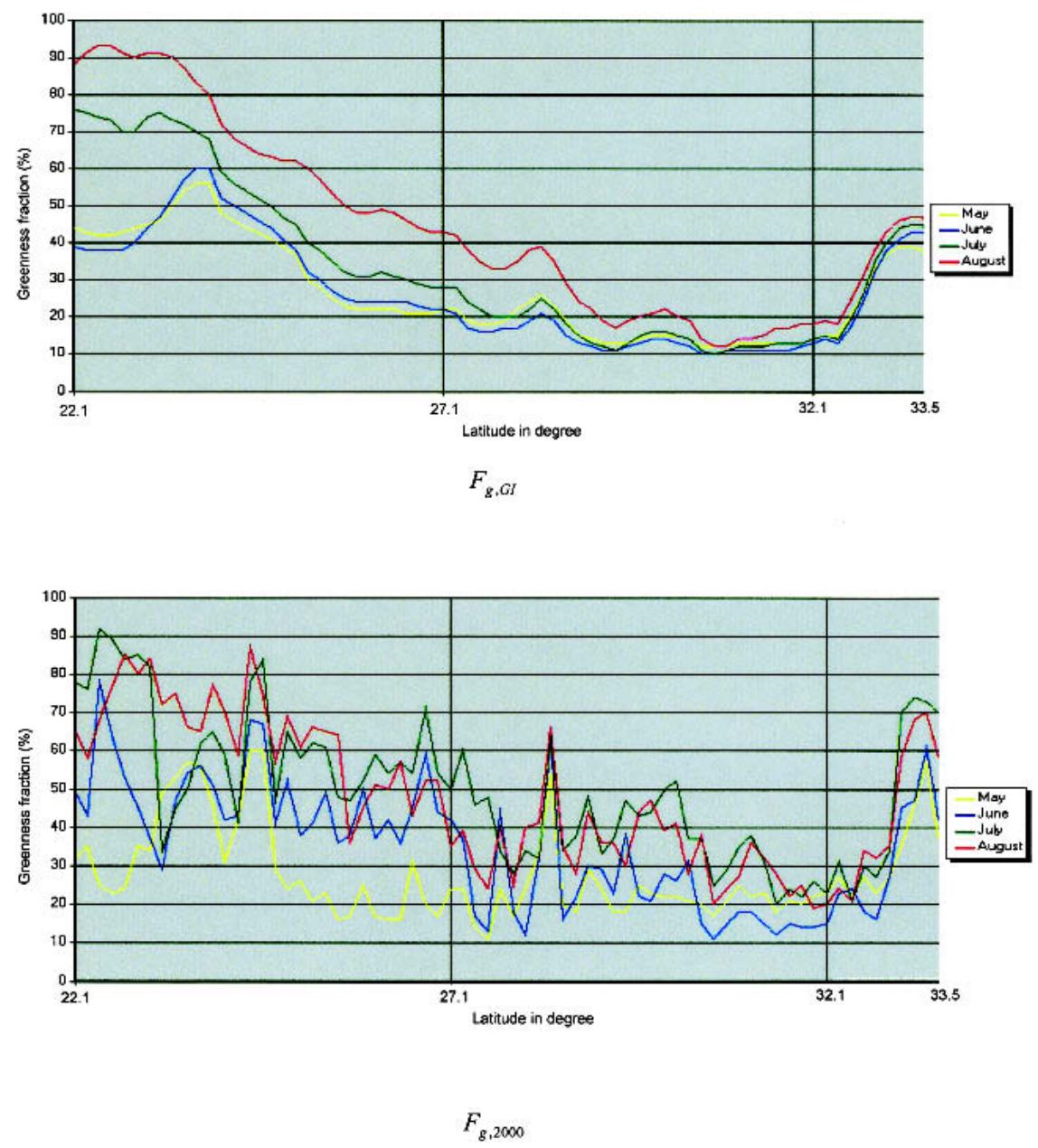

FIG. 1. Cross-sectional analysis of monthly greenness fraction (Fg) from May to Aug. The axes represent the length (degrees) extending from the south $\left(22.1^{\circ} \mathrm{N}, 105.5^{\circ} \mathrm{W}\right)$ to north $\left(33.5^{\circ} \mathrm{N}, 105.5^{\circ} \mathrm{W}\right)$ across the NAMS regions: (top) $\mathrm{Fg}$ from Gutman and Ignatov (1998), and (bottom) the newly derived Fg from GIMMS NDVI. 
differences between $\mathrm{Fg}_{\mathrm{GI}}$ and $\mathrm{FG}_{2000}$ are the degree of their spatial heterogeneity. Due to the coarse horizontal resolution of the global vegetation index dataset (30 $\mathrm{km}), \mathrm{Fg}_{\mathrm{GI}}$ shows the smooth transition from the Sierra Madre Occidental to New Mexico, whereas Fg 2000 shows the sharp transition because of the finer horizontal resolution of the GIMMS NDVI $(8 \mathrm{~km})$. The minimum temporal variability (up to a few percent) over the interior of the northern Mexico from May to July is shown by $\mathrm{Fg}_{\mathrm{GI}}$, whereas $\mathrm{Fg}_{2000}$ shows the greater temporal variability (up to $20 \%$ ) from May to July. Across the western slope of the Sierra Madre Occidental $\left(22^{\circ}-\right.$ $24^{\circ} \mathrm{N}$ ) both data capture the substantial temporal variability (up to $70 \%$ ), although timing of the evolution differs between $\mathrm{Fg}_{\mathrm{GI}}$ and $\mathrm{Fg}_{2000}$. These dissimilarities in the temporal characteristics between $\mathrm{Fg}_{\mathrm{GI}}$ and $\mathrm{Fg}_{2000}$ probably result from the wet-/dry-year variability featured in the 20-yr GIMMS NDVI dataset, compared with the 5-yr-averaged GVI climatology. The overall patterning of the spatial transition in both data during a premonsoon period (May) and a monsoon period ( $\mathrm{Au}-$ gust) are analogous to each other. For example, in $\mathrm{Au}-$ gust, both of the Fg feature the peaks across the Sierra Madre Occidental, with a gradual decrease toward the interior of the northern Mexico, and an increase across southern New Mexico (Fig. 1).

\section{c. Temporal and spatial variability of greenness fraction}

Figure 3 shows a spatial comparison between the dryyear $\left(\mathrm{Fg}_{2000}\right)$ and wet-year $\left(\mathrm{Fg}_{1999}\right) \mathrm{Fg}$ in the NAMS region and southwest United States. The specific study areas considered in this and later sections are the northern NAMS region (NNAMS; $31^{\circ}-36^{\circ} \mathrm{N}, 105^{\circ}-112^{\circ} \mathrm{W}$ ), the southern NAMS region (SNAMS; $24^{\circ}-31^{\circ} \mathrm{N}, 105^{\circ}-$ $112^{\circ} \mathrm{W}$ ), and the Southern Great Plains (SGP; $31^{\circ}-$ $\left.36^{\circ} \mathrm{N}, 95^{\circ}-102^{\circ} \mathrm{W}\right)$. The NAMS region, which is often referred to in this paper, includes both the NNAMS and SNAMS. The SGP is important to examine the contrast of seasonal precipitation against the NAMS region (Higgins et al. 1997). According to the USGS land cover data, the dominant vegetation types are shrub land (95.4\%) over NNAMS; shrub land (55.4\%) and broadleaf deciduous forest $(23.9 \%)$ over SNAMS; and grassland $(48.1 \%)$, savanna $(17.8 \%)$ and broadleaf deciduous forest $(19.6 \%)$ over SGP.

Both $\mathrm{Fg}_{2000}$ and $\mathrm{Fg}_{1999}$ exhibit substantial temporal and horizontal heterogeneity. From June to September Fg increases substantially over the NAMS region. Large wet-/dry-year variability is observed between $\mathrm{Fg}_{2000}$ and $\mathrm{Fg}_{1999}$ in June (Fig. 3). Compared with $\mathrm{Fg}_{2000}, \mathrm{Fg}_{1999}$ in June is significantly lower across the

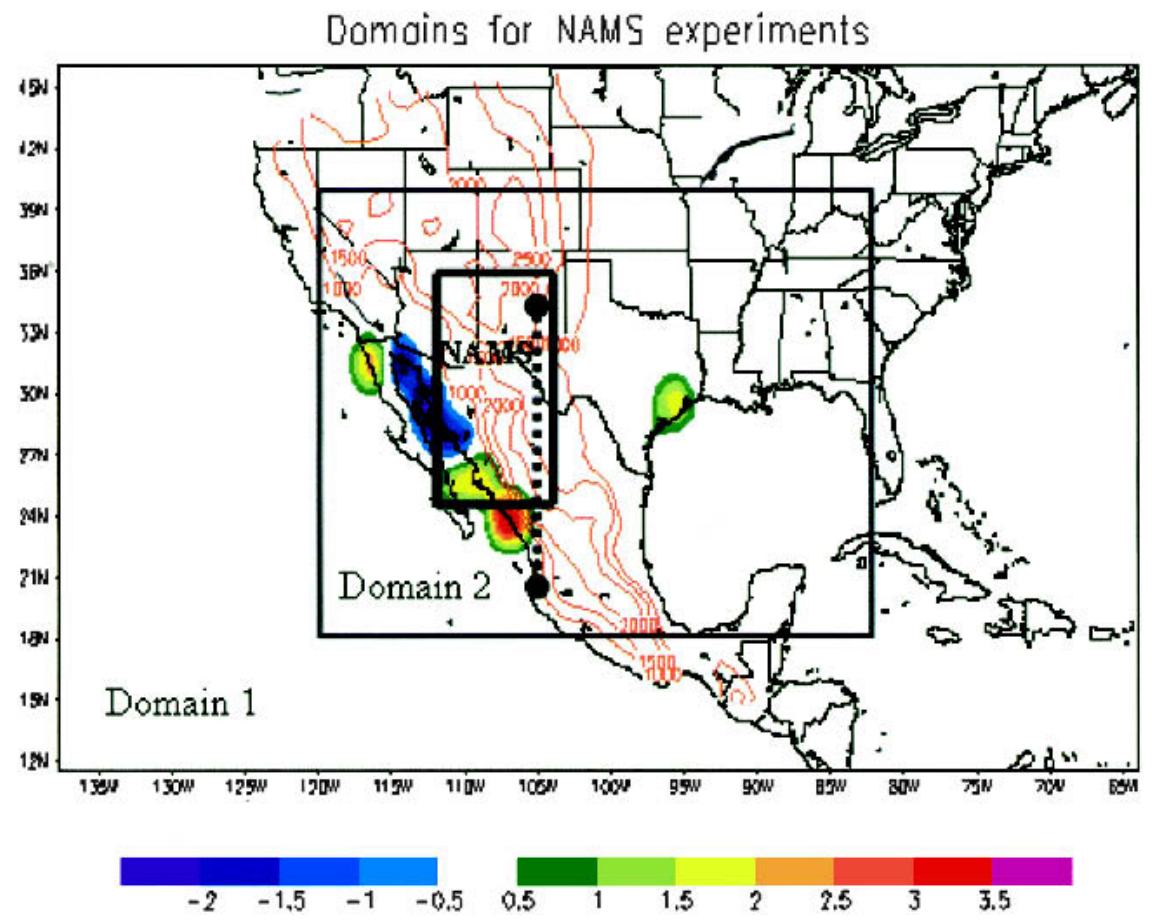

FIG. 2. NAMS region and domains for the MM5-OSU LSM simulation. Domain 1 consists of coarse grids with $90-\mathrm{km}$ spacing and $40 \times 68$ points; domain 2 consists of the nested finer grid with $30-\mathrm{km}$ spacing and $100 \times 70$ points. The inside thick box shows the NAMS region used in the analyses $\left(24^{\circ}-36^{\circ} \mathrm{N}, 112^{\circ}-105^{\circ} \mathrm{W}\right)$. The color shading shows the typical noon temperature difference (K) between the Reynolds SST and NCEP-NCAR reanalysis SST. Orange contours in the continent show the topography $(\mathrm{m})$. Dotted line is used for the cross-sectional analysis of greenness fraction. [Source: Xu and Small (2002).] 

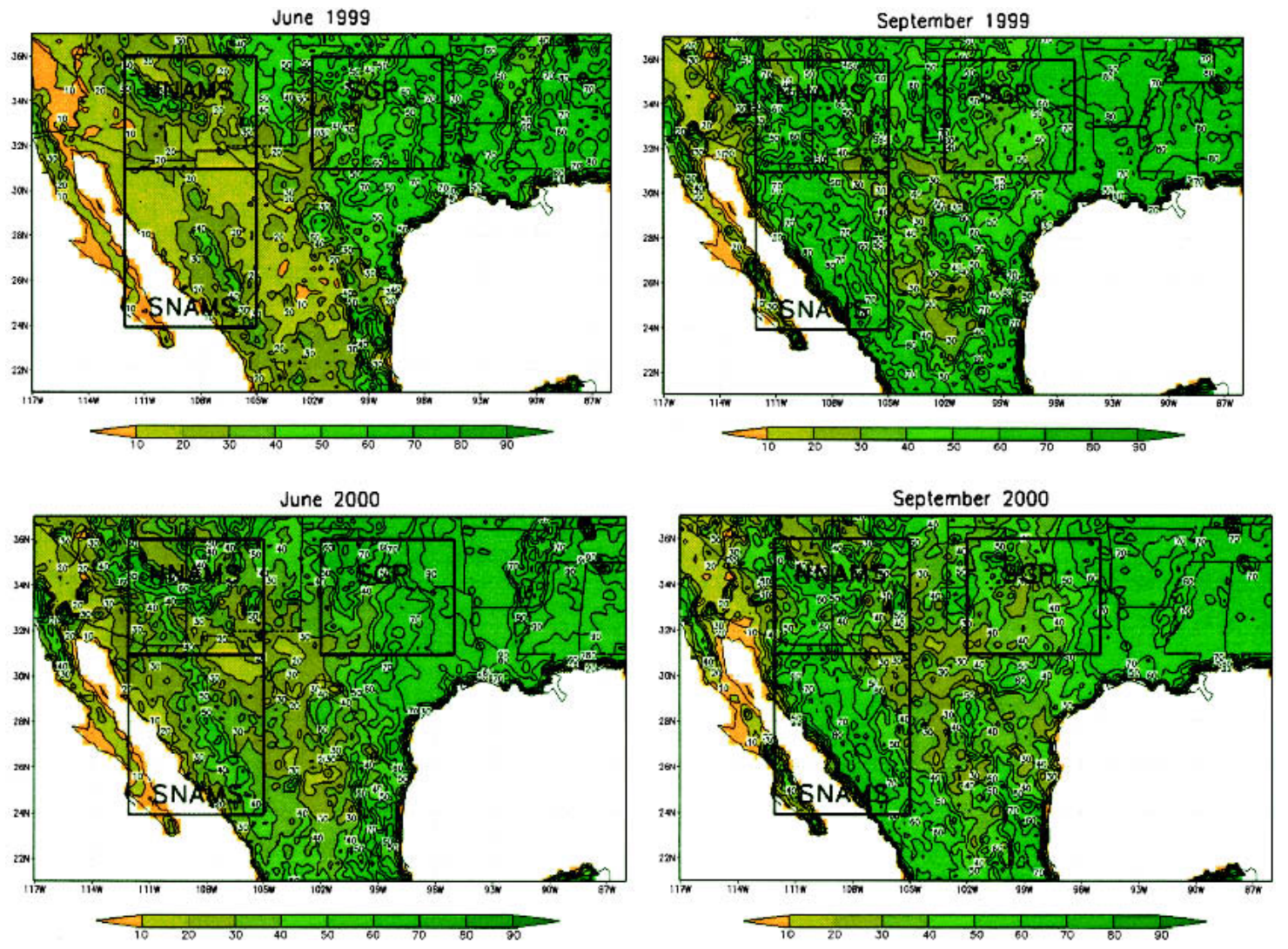

FIG. 3. Spatial distribution of GIMMS NDVI-derived greenness fraction in the MM5-OSU LSM domain 2. The Fg value significantly varies in time and space over the Sierra Occidental and southwest United States.

SNAMS and most of Mexico. The majority of Fg in the NAMS region is approximately less than $20 \%$ in 1999 , indicating dry surface conditions in the premonsoon season. Alternatively, higher $\mathrm{Fg}$ is found in the same month in 2000, indicating a comparatively wet surface condition associated with early onset of the monsoon. In the postmonsoon season (September), $\mathrm{Fg}_{1999}$ in the NAMS region is vividly increased, and becomes greener than that in September 2000. Also, $\mathrm{Fg}_{2000}$ shows a reduction in $\mathrm{Fg}(\sim 20 \%)$ in the SGP and southern United States from June to September. The spatial pattern of variability of Fg could be linked to the characteristics of intraseasonal and wet-/dry-year NAMS precipitation.

Figure 4 shows the temporal rainfall variability linking to the evolution of Fg. In 2000, the NAMS development is weak, especially over the NNAMS $(\sim 1.35$ $\mathrm{mm}$ day $^{-1}$ ). The maximum precipitation is observed in August in the SNAMS (3.34 mm day $\left.{ }^{-1}\right)$. On the other hand, in 1999, NAMS onset is abrupt, and it yields the maximum precipitation in July in the NNAMS and SNAMS (3.17 and $4.59 \mathrm{~mm} \mathrm{day}^{-1}$, respectively); Fg exhibits similar transitions to that of the precipitation. In $2000, \mathrm{Fg}$ is almost invariant over the NNAMS, and an up to $24 \%$ increase is observed over the SNAMS. In
1999, Fg is substantially increased during July and August; up to $30 \%$ and $40 \%$ increases are observed over the NNAMS and SNAMS, respectively. The seasonal plant phenology must be discussed along with vegetation seasonality, water vapor pressure, radiation and temperature. Nevertheless, considering that (i) precipitation anomalies also affect surface vapor pressure and temperature, and (ii) the magnitude of wet-/dry-year anomalies of net radiation is relatively small compared with that of the precipitation, this result suggests that the variability of the NAMS precipitation strongly contributes to the wet-/dry-year and intraseasonal vegetation anomalies. This also motivates us to study the feedback of vegetation variability to the NAMS.

\section{Numerical experiments}

a. Setup

\section{1) Model SETuP}

The MM5-OSU LSM is employed in this study (Grell et al. 1994; Ek and Mahrt 1991; Chen and Dudhia 2001a). The MM5 is a limited-area, sigmacoordinate, nonhydrostatic, mesoscale atmospheric model (Grell et al. 1994). Giorgi and Mearns (1999) 

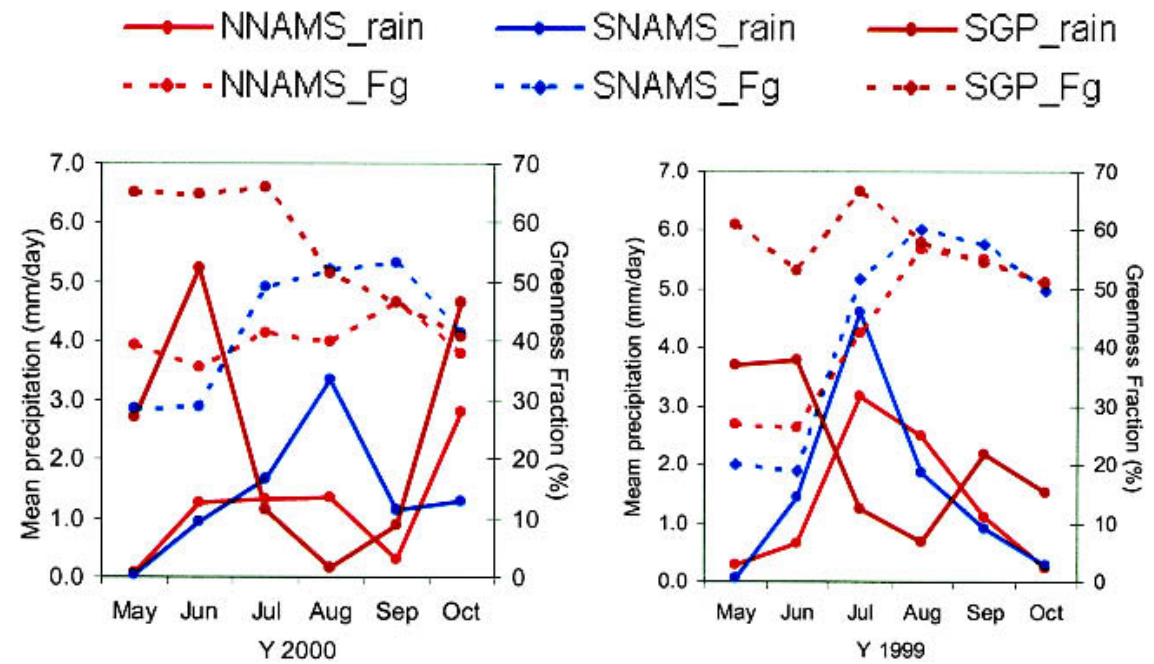

FIG. 4. Time series of gauged precipitation and GIMMS NDVI-derived Fg averaged over the NNAMS, SNAMS, and SGP for (left) 2000 and (right) 1999. Precipitation over the SNAMS and NNAMS shows the abrupt onset of the NAMS and associated growth of the Fg in 1999.

suggest that limited-area RCMs should be carefully customized through the use of observational analysis that drives the model and validates the results before application to the climate studies. The MM5-OSU LSM has been tested for regional climate studies in the NAMS region (Gochis et al. 2002; Small 2001; Xu and Small 2002). Gochis et al. (2002) first reported that the different cumulus convection schemes strongly affect the rainfall simulation in the NAMS simulation during July 1999. Unlike Gochis et al. (2002), Xu and Small (2002) included both the premonsoon and monsoon periods (June 1-September 30) in a wet (1999) and a dry (2000) year, which is critical to studying intraseasonal and wet-/dry-year monsoon variability, in order to customize a combination of radiation and convective schemes, and model domain. They found that the best combination of convection and radiation schemes depends on the time period or synoptic conditions being simulated. For example, the combination of schemes [KainFritsch/Community Climate Model, version 2 (CCM2) radiation] selected by Gochis et al. (2002) was only best for July 1999, a particularly wet month, while it did a relatively poor job in a dry year. Without calibrating the original convection and radiation scheme, $\mathrm{Xu}$ and Small (2002) found that the Grell cumulus convection scheme and the Rapid Radiative Transfer Model (RRTM) scheme predicts precipitation most reasonably during June 1-September 30 in 1999 and 2000. Thus, we employ the exact same combination of the parameterization, domain coverage, and grid size as that of Xu and Small (2002) (Fig. 2).

Grid incremental spaces are 90 and $30 \mathrm{~km}$ in domain 1 and 2, respectively. Domain 1 and 2 are connected in the two-way interaction. The Grell scheme predicts subgrid convective precipitation, which is activated when the grid-scale vertical velocity lifts stable layers past the level of free convection. The convective precipitation depends on the condensation in the updraft, the mass flux of the updraft, and an efficiency parameter. This scheme tends to allow a balance between the resolved-scale rainfall and the convective rainfall (Grell 1993). Simple three-class microphysics is used to predict a resolved-scale cloud and precipitation (Dudhia 1989). RRTM uses a $K$-correlated factor to predict longwave radiation in an efficient manner (Mlawer et al. 1997).

The OSU LSM coupled with Medium Range Forecast (MRF) PBL scheme is used to predict the surface hydrology, energy flux, and evolution of the PBL. The OSU LSM incorporates the diurnally dependent Penman potential evaporation scheme, the four-layer soil model $(0.1,0.3,0.6$, and $1.0 \mathrm{~m})$, the primitive single canopy model, and a moderately complex canopy resistance approach (Ek and Mahrt 1991; Chen et al. 1996; Chen and Dudhia 2001a; Jacquemin and Noilhan 1990; see appendix). MRF PBL uses nonlocal $K$ correlated turbulence scheme, which is suitable for the convective boundary layer (Hong and Pan 1996). The OSU LSM combined with MRF PBL scheme can reproduce reasonable daytime land surface energy flux and associated PBL growth (Chen and Dudhia 2001b), which allow us to examine the influence of surface energy flux on the BL and the associated cumulus convection.

A number of datasets are used to initialize MM5OSU LSM: the USGS global digital elevation model (DEM), USGS 25-category global vegetation/land cover data, USDA State Soil Geographic Database (STATSGO) 17-category global soil-type data (Miller and White 1998) combined with Food and Agriculture 
TABLE 1. Design of experiments.

\begin{tabular}{clc}
\hline \hline Experiment & \multicolumn{1}{c}{ Fg state } & Year of Fg \\
\hline DYN & Dynamic & 2000 \\
FIX & Fixed on 1 Jun & 2000 \\
DIFF & Dynamic & 1999 \\
\hline
\end{tabular}

Organization (FAO) global soil data (Zobler 1986). As Eqs. (A1.1), (A1.2), and (A1.3) in the appendix demonstrate, NDVI-derived $\mathrm{Fg}$ is used to determine the partitioning of evaporation/transpiration (ET) into the three components: bare soil evaporation $\left(E_{\mathrm{dir}}\right)$, evaporation from raindrops trapped on the canopy $\left(E_{c}\right)$, and transpiration via stomata $\left(E_{t}\right)$. The National Centers for Environmental Prediction (NCEP)-NCAR reanalysis (Kalnay et al. 1996) is used for the lateral and initial atmospheric boundary conditions, including soil moisture. The reanalysis is downscaled to force the MM5 coarse domain at every model time step. The $1^{\circ}$ Reynolds sea surface temperature (SST) is made available at 6-h intervals (Reynolds and Smith 1994). The Reynolds SST reproduces less biased SST in the Gulf of California without mixing land surface temperature ( $\mathrm{Xu}$ and Small 2002) (Fig. 2).

\section{2) EXPERIMENT DESIGN}

We incorporate the observed Fg boundary conditions into the MM5-OSU LSM to examine the sensitivity of the NAMS simulations. We examine the influence of (a) intraseasonal and (b) wet-/dry-year Fg variability on surface flux and regional/local atmosphere using the MM5-OSU LSM. The soil moisture and atmospheric state evolve freely throughout each experiment, while vegetation conditions are assigned to force a one-way interaction from vegetation to atmosphere. In other word, variability of $\mathrm{Fg}$ is prescribed according to observations, regardless of the simulated soil moisture, radiation, and temperature states. In the use of the RCM, we need to note that the "freedom" of domain clima- tology should be stated as "climatological sensitivities from the forcing field," because lateral boundary conditions (LBCs) prevent the domain climate from drifting much away from the climate represented by the LBCs (Giorgi and Mearns 1999).

Numerical simulations are initialized on 1 June 2000 and run continuously through 30 September. In this study, we selected a dry year (2000) for the experiment. An experiment using the boundary conditions from a dry year should most clearly show the influence of the land surface state. In wet years, the strong monsoonal moisture transport could overwhelm the land surface influence in the NAMS region. On the seasonal time scale, there is a dramatic increase $(>20 \%)$ in $\mathrm{Fg}$ over the SNAMS in 2000, whereas seasonal variations in the NNAMS are minor (Fig. 4). On the wet-/dry-year time scale, Fg is much lower in the NNAMS during 2000 than during the wet year of 1999, from which Fg boundary conditions are derived in one of the experiments. In contrast, Fg is relatively similar in 2000 and 1999 in the SNAMS. These substantial differences in observed Fg fluctuations in NNAMS and SNAMS demonstrate the complexity of vegetation variability.

Three experiments are defined as follows. Throughout a simulation, the dynamic (DYN) monthly Fg from the year 2000 is linearly interpolated and updated every $24 \mathrm{~h}$; the Fg is prescribed according to the value on 1 June 2000 and does not vary (FIX) throughout the simulation; the monthly Fg of different year (1999) (DIFF) is linearly interpolated and updated every $24 \mathrm{~h}$ (Table 1). Figure 5 displays the variations of $\mathrm{Fg}$ in the three experiments in the NNAMS, SNAMS, and SGP. The dynamic simulation is designed to represent what is observed during 2000. A comparison of the dynamic and fixed $\mathrm{Fg}$ shows the effects of the intraseasonal plant phenology: greening up during monsoon in NAMS region and senescence in SGP. Comparison of the dynamic with the different year (1999) shows how the wet-/dry-year fluctuations of vegetation influence the land-atmosphere coupling. The wet-/dry-year response
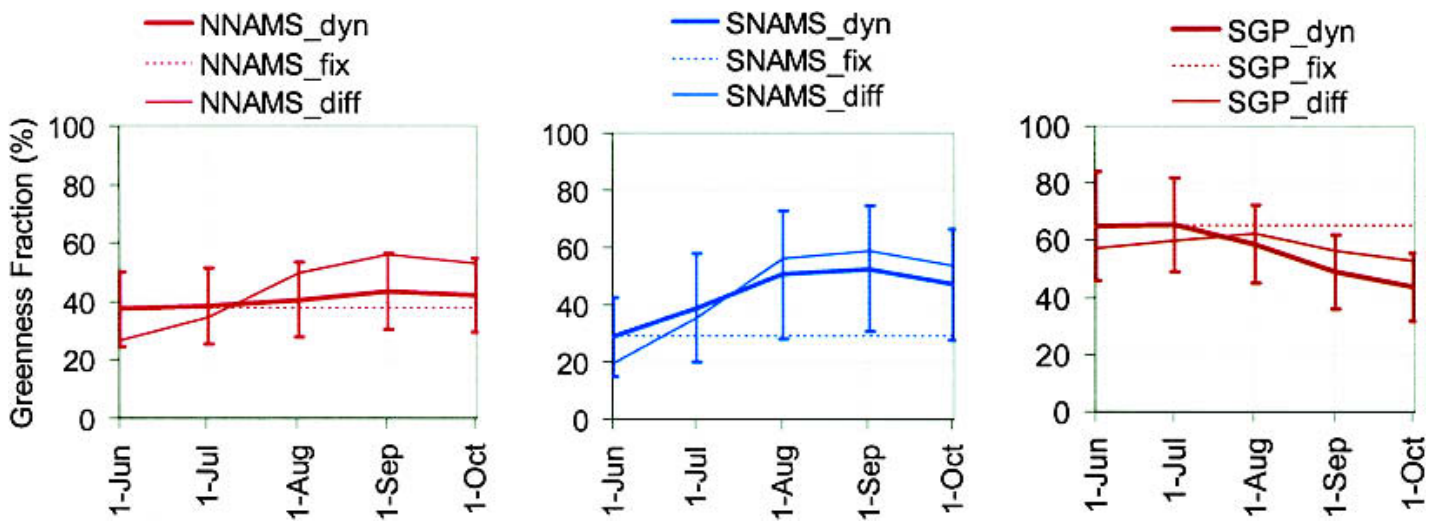

FIG. 5. Transitions of the different Fg boundary conditions in the SNAMS, NNAMS, and SGP. Error bars shows spatial std dev. 
should be minimal for the SNAMS, where 2000 and $1999 \mathrm{Fg}$ is similar (Fig. 5). However, for NNAMS, Fg is much higher for 1999; if vegetation is free from the severe stress, we expect that the 1999 Fg should increase ET, which induces unstable BL energy to permit a greater probability of moist convection in this region.

\section{b. Results}

\section{1) Simulated PATTERN OF PRECIPITATION AND MOISTURE FLUX}

Four-month-long (from June to September) simulations are carried out for 2000 over the NAMS domain. First, we describe the spatial pattern of the simulated precipitation $\left(\mathrm{mm} \mathrm{day}^{-1}\right)$ and lower-troposphere (sigma level $=0.995-0.910)$ moisture flux $\left(\mathrm{kg} \mathrm{m} \mathrm{kg}^{-1}\right.$ $\mathrm{s}^{-1}$ ) over the model domain from the control simulation (DYN) (Fig. 6).

In June, a strong southerly moisture flux from the Gulf of Mexico, associated with the Great Plains lowlevel jet (LLJ), contributes to the large amount of precipitation over the SGP and southern United States. This moisture flux also increases the precipitation in the vicinity of the NAMS region and the SGP. Compared with the observed precipitation, the MM5-OSU LSM overestimated the precipitation (up to $2.27 \mathrm{~mm} \mathrm{day}^{-1}$ ) in the SNAMS, while it underestimated the precipitation (up to $2.60 \mathrm{~mm} \mathrm{day}{ }^{-1}$ ) in the SGP (Table 2). In July, Great Plains LLJ-related southerly moisture flux in the SGP is suppressed corresponding to the enhanced easterly in the northern Gulf of Mexico. As a result, the SGP experience a drying trend. Observed rainfall over the SGP also shows the strong reduction in precipitation from June to July of $4 \mathrm{~mm}$ day $^{-1}$. This seasonal transition of the modeled moisture flux between the NAMS region and SGP is analogous to the multiyear analysis with the NCEP-NCAR reanalysis (Higgins et al. 1997). Reduced southeasterly moisture flux from the Gulf of Mexico is also linked to the suppressed precipitation in the NNAMS, which is lower than the observed precipitation rate (up to $0.88 \mathrm{~mm}$ day $^{-1}$; Table 2). In August, precipitation is dominantly affected by the track of tropical cyclones. The southeasterly moisture flux associated with tropical cyclones from the Gulf of Mexico yields a large amount of precipitation along the Gulf of Mexico. Southerly moisture
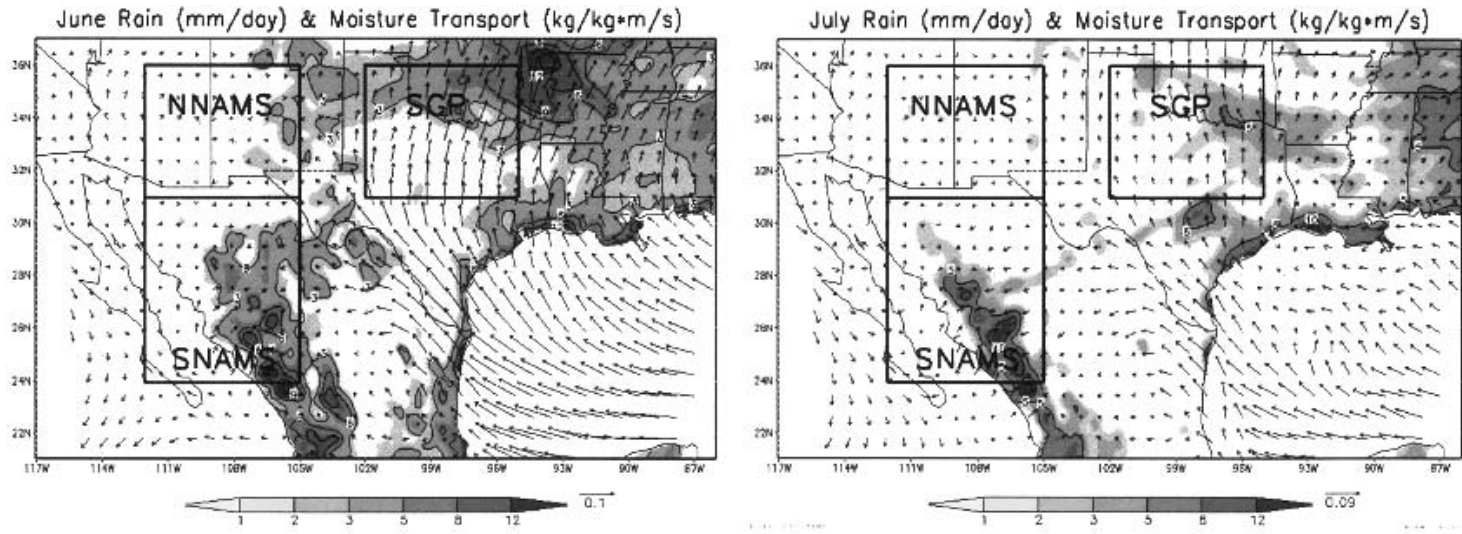

August Roin (mm/day) \& Moisture Transport $(\mathrm{kg} / \mathrm{kg} * \mathrm{~m} / \mathrm{s}$ )
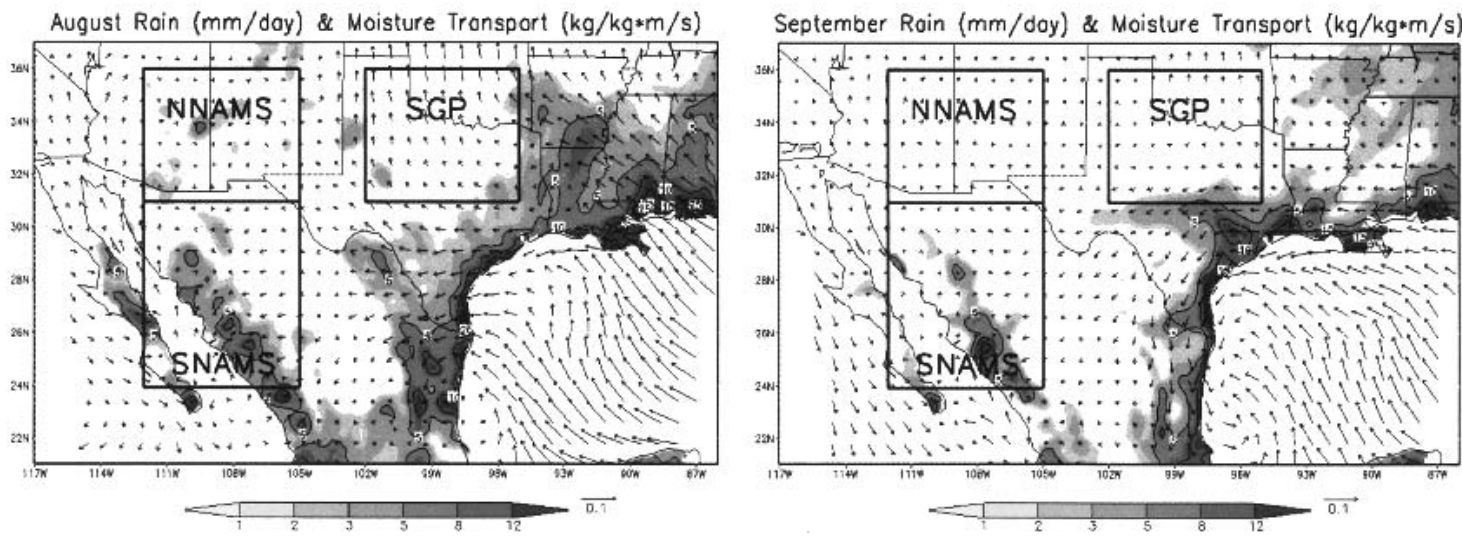

FIG. 6. Monthly precipitation ( $\mathrm{mm} \mathrm{day}^{-1}$; shaded) and near-surface (sigma level $=0.995-0.910$ ) vector moisture flux $\left(\mathrm{kg} \mathrm{m} \mathrm{kg}^{-1} \mathrm{~s}^{-1}\right)$ from Jun to Sep in the DYN experiment. 
TABLE 2. Simulated precipitation versus observed gauged precipitation averaged over the NNAMS, SNAMS, and SGP in 2000.

\begin{tabular}{|c|c|c|c|c|c|c|c|c|c|c|c|c|}
\hline & \multicolumn{4}{|c|}{ NNAMS } & \multicolumn{4}{|c|}{ SNAMS } & \multicolumn{4}{|c|}{ SGP } \\
\hline & Gauge & DYN & FIX & DIFF & Gauge & DYN & FIX & DIFF & Gauge & DYN & FIX & DIFF \\
\hline Jun & 1.24 & 1.06 & 1.17 & 0.95 & 0.93 & 2.73 & 3.20 & 2.41 & 5.23 & 2.63 & 2.75 & 2.70 \\
\hline Jul & 1.29 & 0.66 & 0.41 & 0.58 & 1.64 & 2.35 & 1.99 & 1.84 & 1.14 & 1.86 & 1.47 & 1.19 \\
\hline Aug & 1.35 & 1.09 & 1.19 & 1.10 & 3.34 & 2.33 & 2.74 & 3.31 & 0.15 & 0.75 & 0.20 & 0.39 \\
\hline Sep & 0.30 & 0.19 & 0.99 & 0.44 & 1.14 & 1.83 & 2.49 & 1.56 & 0.88 & 0.47 & 0.75 & 0.21 \\
\hline Seasonal & 1.04 & 0.75 & 0.94 & 0.76 & 1.76 & 2.31 & 2.61 & 2.28 & 1.85 & 1.43 & 1.29 & 1.12 \\
\hline
\end{tabular}

flux in the northern Gulf of California converges with the northeasterly from northwestern Pacific to generate a tropical cyclone, which enhances precipitation across the Baja California and the NAMS region. Simulated precipitation in August in the NNAMS, SNAMS, and SGP is reasonable compared with the observed precipitation (Table 2). In September, the southerly moisture flux is shifted in the southern edge of the Gulf of California. The observed precipitation also exhibits the significant reduction in precipitation, on the order of $1 \mathrm{~mm}$ day $^{-1}$ from August and September (Table 2).

In general, the control simulation (DYN) captures the characteristic patterning of the moisture flux and precipitation in the NNAMS, SNAMS, and SGP, compared with the NAMS climatology in Higgins et al. (1997). Throughout the season, the differences from observed precipitation values are common to the three different experiments (DYN, FIX, and DIFF) (Table 2). There is one exception to this result. In September, the FIX experiment greatly overestimated the precipitation in the SNAMS and NNAMS (0.69 and $1.35 \mathrm{~mm}$ day ${ }^{-1}$, respectively), while the other simulations yielded more reasonable estimates. Detailed mechanism of this sensitivity is discussed in section $3 b(5)$.

\section{2) Time SERIEs of Regional WATER BUdget}

We examine the temporal variations of cumulative precipitation, volumetric soil moisture, and 5-day running mean evaporative fraction (EF) simulated from June to September 2000 at the regional scale. Output at noon (0000 mountain time) is chosen for the EF and soil moisture data analysis. Figure 7a depicts cumulative precipitation averaged over the NNAMS, SNAMS, and SGP for the DYN, FIX, and DIFF experiments. There are small differences in precipitation. At the end of June, the FIX experiment yields the largest precipitation, while DIFF experiment yields the lowest precipitation. However, this difference is diminished at the middle of August; cumulative precipitation in the three experiments becomes identical at this time. On 21 July, in the SGP, a notable rainfall yields the greatest precipitation in the DYN experiment, while it yields the least precipitation in the DIFF experiment. Since 21 July, the order of cumulative precipitation between the three experiments is invariable after this event. There are no substantial differences in precipitation between the experiments, except over the NAMS regions in September and the SGP in July.
Figure $7 \mathrm{~b}$ shows how the seasonal variations of volumetric soil moisture at $0-60 \mathrm{~cm}$ are quite different among the three regions. Soil moisture in the SNAMS gradually increases through the season, while soil moisture in the SGP gradually decreases through the season. It closely features the dipole structure of precipitation between the NAMS regions and the Great Plains (Higgins et al. 1997). Soil moisture is consistently below 0.14 over the NNAMS, with a smaller range of temporal fluctuation than either the SGP or SNAMS. The differences in temporal variations of soil moisture between the three experiments are linked to the differences in precipitation (Figs. 7a and 7b). For example, in the SNAMS, the FIX experiment yielded greater soil moisture at the end of July, while the DIFF experiment yielded the lowest soil moisture. This order is diminished at the middle of August. On 9 August, the FIX experiment substantially increased soil moisture in the NAMS region.

Figure $7 \mathrm{c}$ shows the 5-day running mean EF. Temporal transition of EF between the regions and experiments are analogous to those of precipitation and soil moisture, except in the SNAMS. Until mid-August EF is much lower in the NAMS region, compared with the SGP. This means that sensible heat flux dominates the surface turbulent energy flux in the NAMS regions. Even though soil moisture in the SNAMS becomes higher than that in the SGP after the middle of July, EF in the SNAMS consistently remains low $(<0.5)$ throughout the season. Indeed, as opposed to our expectation, in the SNAMS, the FIX experiment (with lower Fg boundary conditions) yields a slightly, but consistently, higher precipitation, soil moisture, and EF throughout the season. This shows that the simulated climate does not include a positive feedback between vegetation anomalies and precipitation at the regional scale. Instead, a negative feedback exists: higher fractional vegetation cover suppresses EF and precipitation, which would minimize the vegetation anomaly if two-way interactions between $\mathrm{Fg}$ and rainfall were included in the model (Eastman et al. 2001).

\section{3) Local SCALE Fluctuations (GRID-BY-GRID ANALYSIS)}

Betts and Ball (1998) demonstrated that a greater ET leads to a higher EF, a lower afternoon planetary boundary layer (PBL) height, and lifting condensation level (LCL). Therefore, the same amount of the avail- 

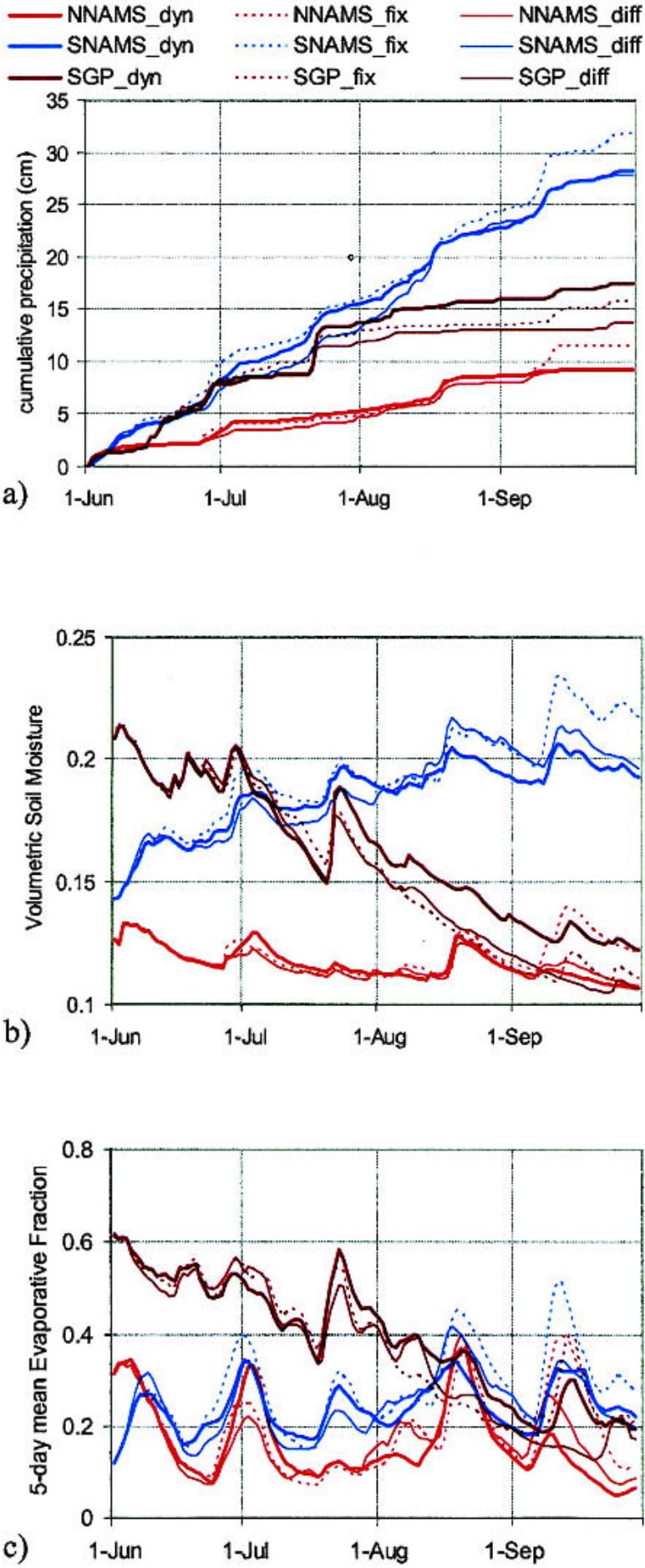

FIG. 7. Time series of simulated cumulative precipitation, soil moisture, and 5-day running mean EF over the NNAMS, SNAMS, and SGP in the three experiments. The transitions of three variables are analogous to each other, demonstrating the land-atmosphere interaction. able energy is transferred into the shallower PBL, which is more likely to trigger the moist convection (Betts and Ball 1998). Eltahir (1998) proposed that the changes in the surface albedo and surface temperature play an important role in moisture feedback. Wet soil or vegetation increases net radiation due to the darkened land surface and lower surface temperature, and more energy is available for atmospheric turbulent heat flux into the PBL. Using ground observations from shrub land and grassland environments in the NAMS region, Small and Kurc (2003) reported that midday net radiation and available energy were higher by $\sim 20 \%$ on days with the wettest soils, compared to dry conditions, due to a decrease in surface temperature and emitted longwave radiation. Because moist convections are also affected by a combination of the sea breeze, orographic lifting, and large-scale monsoon circulation, it is critical to re-evaluate the aforementioned onedimensional feedback in the NAMS region.

Seasonally averaged Fg and ET are compared with the surface energy/moisture flux, lower atmosphere condition, and rainfall over the NAMS regions at the local scale (grid-by-grid at $900 \mathrm{~km}^{2}$ ). Scatterplot analyses are designed to examine (a) the influence of intraseasonal anomalies of $\mathrm{Fg}$ from the difference between the DYN and FIX experiments (DYN - FIX) and (b) the influence of wet-/dry-year anomalies of Fg from the difference between the DYN and DIFF experiment (DYN - DIFF). The correlation coefficient of scatterplots indicates the feedback at the regional scale, and positioning of each scatter point indicates the feedback at local scale. Figure 8 shows a scatterplot between the seasonally averaged Fg and precipitation. The correlation coefficients between Fg and precipitation are 0.013 and 0.09 for DYN - FIX and DYN DIFF, respectively. As we found in the previous section, this suggests that there is no correlation between the Fg and the precipitation at the regional scale. According to the proposed pathway, most of the scattered points should be located in the positive feedback regions, indicated as "+" in the Fig. 8; nevertheless, these figures show that the positive and negative feedback coexist at the local scale in the NAMS region. The DYN - FIX plot, in fact, shows that the scattered points tend to be located in the negative feedback zones indicated as "-" in the Fig. 8. In the simulations examined here, the influence of $\mathrm{Fg}$ variability on the precipitation does exist at the local scale.

There are two possible explanations for this result: 1) higher ET and EF does not consistently enhance rainfall, and 2) higher Fg does not consistently enhance ET and EF. The first explanation is assessed by examining the relationship between ET and surface energy flux, BL conditions, and rainfall. The correlation coefficients in Table 3 show that the expected pathway is demonstrated by the MM5-OSU LSM; for example, greater ET and EF lead to a lower surface temperature, shallower PBL height, higher near-surface $\mathrm{RH}$, higher 

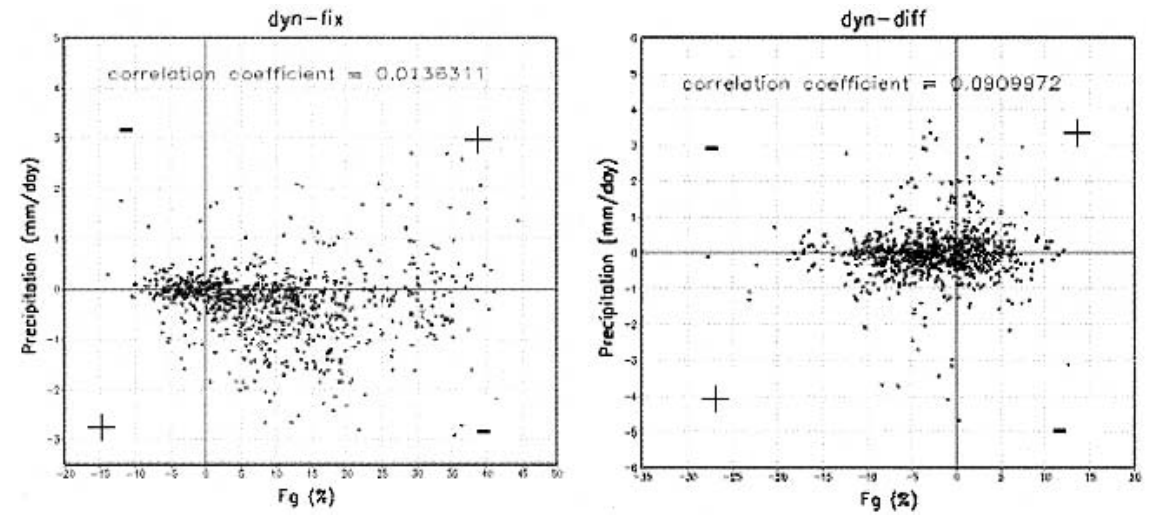

FIG. 8. Scatterplots of seasonally averaged local precipitation and Fg across the NAMS regions. (left) DYN - FIX examines the sensitivity of simulated precipitation to the intraseasonal variability of Fg. (right) DYN - DIFF examines the sensitivity of the simulated precipitation to the interannual variability of Fg: "+" indicates positive feedback, while "-" indicates negative feedback.

equivalent potential temperature $\left(\theta_{e}\right)$, and greater precipitation. These relationships have a high correlation coefficient $(\sim 0.95)$, although the atmospheric variables have weaker correlations due to horizontal advection. Of course, it is not possible to establish a cause-effect relationship between ET and precipitation anomalies using the results from our experiments; ET and rainfall may be positively correlated, simply because rainfall increases soil moisture and, therefore, ET. However, the ET-rainfall relationship does not refute the proposed linkage. Thus, the results are consistent with the soil moisture positive feedback theory via changes in the BL state. This examination also demonstrates that a coupled surface-PBL convection scheme in the MM5OSU LSM can represent such soil moisture feedback theory, which is consistently observed in the First International Satellite Land Surface Climatology Project (ISLSCP) Field Experiment (FIFE) site (Betts and Ball 1998; Eltahir 1998).

The second explanation is examined by assessing the relationship between seasonal Fg and ET (Fig. 9). The scatterplots discern that higher Fg does not consistently enhance ET and EF, because a negative and positive feedback coexist at the local scale. Similar to Fig. 8, the difference between the DYN and FIX simulations shows that higher Fg tends to suppress ET and EF at the regional scale (correlation coefficient $=-0.13$ ) and most of the individual grid cells in the NAMS region. In the simulations examined here, seasonal growth of veg- etation over the NAMS region lowers the simulated EF (Fig. 7a). This result explains why seasonal Fg growth suppresses precipitation at the regional scale, particularly in the SNAMS, as described in section $3 b(2)$. Given this result, we examined how changes in Fg alter the simulated partitioning of total ET into evaporation from the top soil layer $\left(E_{\mathrm{dir}}\right)$, evaporation of precipitation trapped by the canopy $\left(E_{c}\right)$, and transpiration via plant stomata $\left(E_{t}\right)$.

\section{4) Canopy resistance, EF, and soil moisture}

In this section, we examine why higher $\mathrm{Fg}$ does not enhance total ET and which controlling factors [Eq. (A.4) in the appendix] suppress transpiration in the simulations. Figure 10a exhibits the time series of logarithmic canopy resistance index averaged over the NNAMS, SNAMS, and SGP in each experiment. In the SNAMS and NNAMS, the canopy resistance factor is consistently higher throughout the season, compared to that of the SGP. The appendix describes the series of equations used to calculate the canopy resistance term, which is a function of temperature, radiation, water vapor, and soil moisture factor [Eqs. (A.4)-(A.8)]. We saved the modeled data for the four resistance factors in the DYN simulation from June to August. Table 4 summarizes seasonally averaged canopy resistance factors in each region. In this case, lower values of the factors reflect higher plant stress that results in lower transpiration. Solar radiation and temperature factors

TABLE 3. A series of correlation coefficients. Seasonally averaged local evapotranspiration is compared with EF, temperature, relative humidity, PBL height, equivalent potential temperature $\left(\theta_{e}\right)$, and precipitation across the NAMS regions. Each relationship has a high correlation coefficient value for both "DYN - FIX" and "DYN - DIFF."

\begin{tabular}{ccccccc}
\hline \hline Evapotranspiration & EF & Ts $(\mathrm{K})$ & RH $(\%)$ & PBL height & $\theta_{e}$ & Precipitation \\
\hline DYN - FIX & 0.92 & -0.68 & 0.48 & -0.54 & 0.36 & 0.65 \\
DYN - DIFF & 0.95 & -0.81 & 0.72 & -0.723 & 0.41 & 0.71 \\
\hline
\end{tabular}



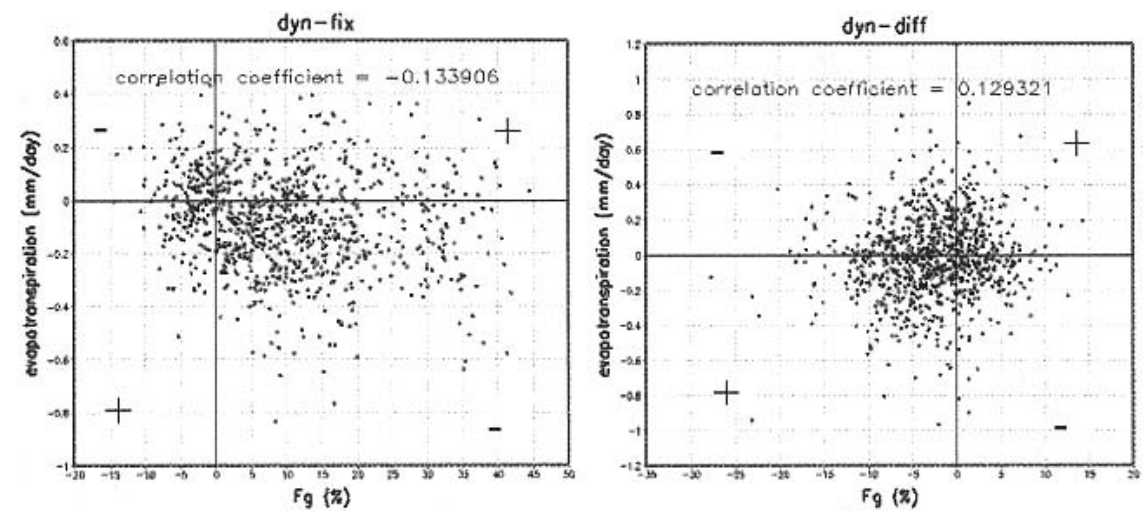

FIG. 9. Scatterplots of seasonally averaged local Fg and evaporation across the NAMS regions. Higher Fg does not necessarily enhance ET and EF for DYN - DIFF. Higher Fg, rather, suppresses the EF for DYN - FIX. The "+" and "-" symbols are the same as in Fig. 8.

are close to 1 (least stress) over the SNAMS, NNAMS, and SGP, although SGP shows weak stress $(0.85)$ from solar radiation, probably due to cloud cover. Water vapor shows the stress index around 0.6. While the aforementioned three factors show a similar stress index between the regions, the soil moisture factor is by far the lowest and different between the regions $(0.27,0.17$, and 0.42 over the NNAMS, SNAMS, and SGP, respectively). These low values strongly increase the canopy resistance term. The soil moisture factor is calculated as a function of the full range of soil moisture between the wilting and reference point. As explained in the appendix, the wilting point of the range was lowered in these simulations to represent subgrid variability in soil moisture (Chen and Dudhia 2001a). Even with this modifi- cation, transpiration is greatly reduced by soil moisture stress. A time series of the soil moisture stress factor shows that differences between the regions are largest at the beginning of simulations, and then tend to decrease toward the end of the simulations $(\sim 0.23)$ (Fig. 10b). However, the region-to-region differences in the total canopy resistance term are still very large on 1 September (note that the value is plotted on a logarithmic scale), even though the values for the soil moisture stress factor are nearly identical (Figs. 10a and 10b). This is the result of differences in the minimum stomatal resistance $\left(R_{c \text { min }}\right)$ between the prescribed vegetation types, derived from Dickinson et al. (1993).

We now examine the relationship between EF and soil moisture at the local scale, to further assess how Fg a)

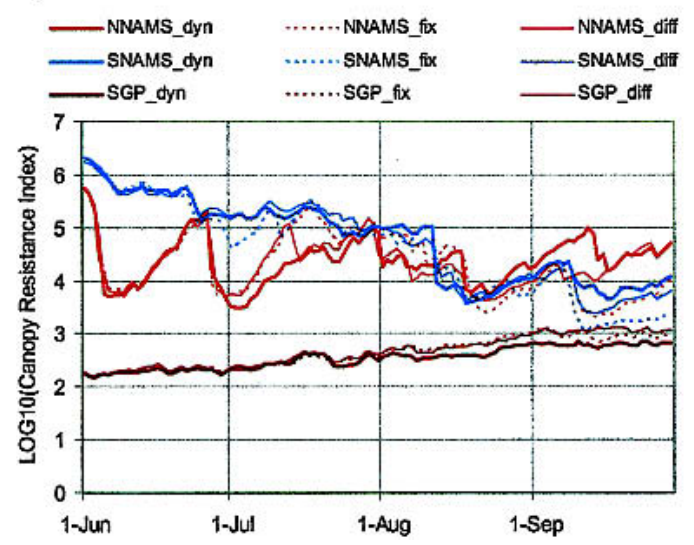

b)

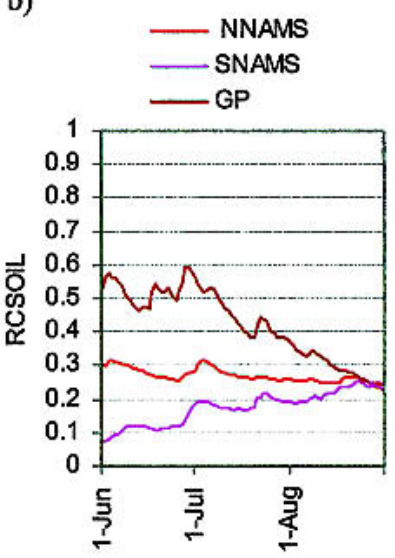

FIG. 10. (a) Time series of $\log _{10}$ (canopy resistance) averaged over the NNAMS, SNAMS, and SGP. Canopy resistance is consistently high in the SNAMS and NNAMS. These high resistances stifle the transpiration during the simulation. (b) Time series of soil moisture resistance factor averaged over the NNAMS, SNAMS, and SGP in the DYN simulation. The soil moisture deficit factor is very low in the SNAMS and NNAMS; soil moisture is close to wilting point in the SNAMS and NNAMS. 
TABLE 4. Seasonally averaged resistance factors averaged over the NNAMS, SNAMS, and SGP. Soil moisture factors are very low in the NNAMS and SNAMS.

\begin{tabular}{lccc}
\hline \hline Resistance factor & NNAMS & SNAMS & SGP \\
\hline Solar radiation & 0.91 & 0.93 & 0.85 \\
Temperature & 0.97 & 0.96 & 0.90 \\
Water vapor & 0.59 & 0.61 & 0.63 \\
Soil moisture & 0.27 & 0.17 & 0.42 \\
\hline
\end{tabular}

influences ET and EF. We plot the seasonally averaged local EF and soil moisture within the NAMS regions, combining data from the DYN, FIX, and DIFF experiments. The scatterplot forms several discernible groups, which represent a different soil type (Fig. 11a). The strong control of EF by soil type and soil moisture exists because both the bare soil evaporation and the transpiration soil moisture stress factor are a function of the soil moisture between the wilting point and the reference point [Eqs. (A.1) and (A.9)]. We grouped grid cells with $\mathrm{Fg}$ in low, middle, and high fractions, with the different threshold values between shrub and tree surface types. Figure 11b provides an EF soil moisture plot for grid cells with trees, including deciduous broadleaf, evergreen broadleaf, evergreen needleleaf, and mixed forest on the silty clay loam soil type. These grid cells are mostly located across the western slope of Sierra Madre Occidental. This plot shows that higher Fg yields lower $\mathrm{EF}$, while bare ground leads to higher $\mathrm{EF}$, with the greatest contrast for lower soil moisture levels. A similar result exists for grid cells with shrub land cover and the silty clay loam soil type (Fig. 11c) and other soil types (not shown here). In all cases, the vegetation fraction does not influence EF to any significant degree, because the points for different Fg classes are intermixed (Figs. 11b and 11c). With a given soil moisture initial condition and transpiration parameterization in the OSU LSM, soil moisture and soil texture shows the stronger effect on the EF in the NAMS region.

In this study, we represented variations in vegetative state by prescribing vegetation fraction, because this is the controlling variable in the OSU LSM. Prescribing variations in LAI, or a combination of LAI and vegetation cover, may yield different impacts on simulated surface energy and water flux. However, as shown in Fig. 10a and Eq. (A.4) in the appendix, the canopy resistance terms are highly restricted (note values are plotted on a logarithmic scale). Thus, incorporation of variable LAI in the OSU LSM should be completed together with the calibration of the transpiration parameterization.

\section{5) Modulation of Regional ATMOSPHERIC CIRCULATION}

In this section, we examine the mechanism of the FIX experiment that causes greater moist convection in the NAMS region in the middle of September. Figure 12a a)

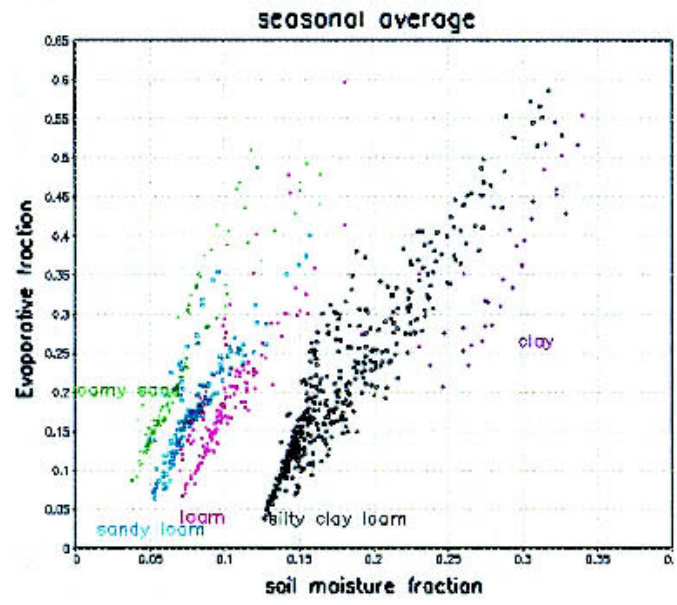

b)

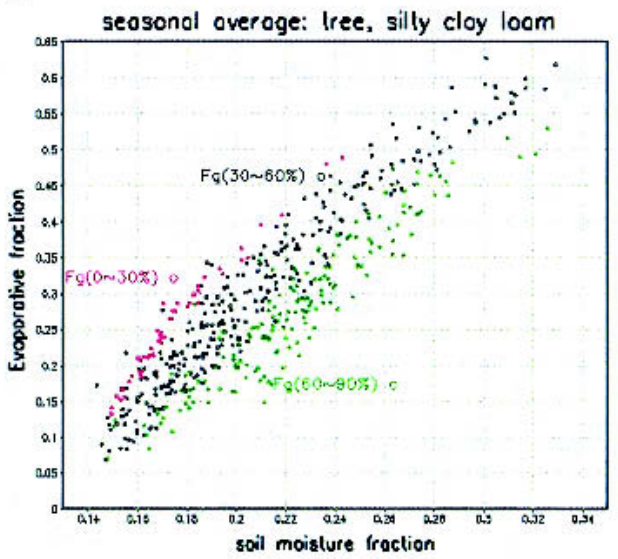

c)

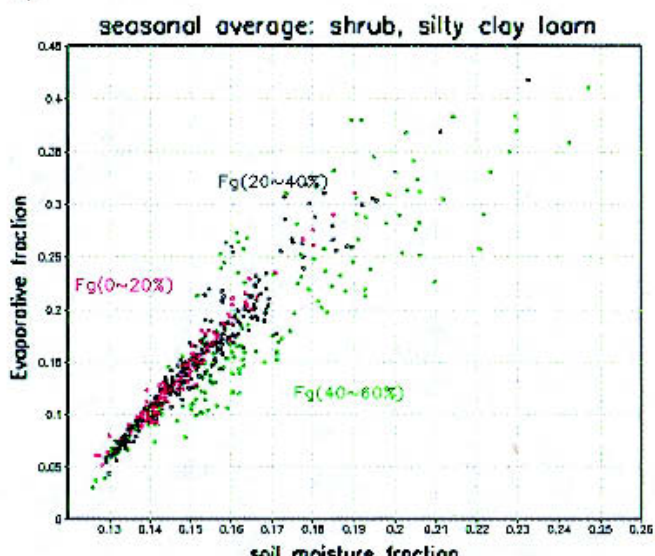

FIG. 11. Scatterplots of seasonally averaged local soil moisture and EF across the NAMS regions (three experiments are combined). These scatterplots are clustered according to the (a) soil types and (b), (c) Fg. 
a)

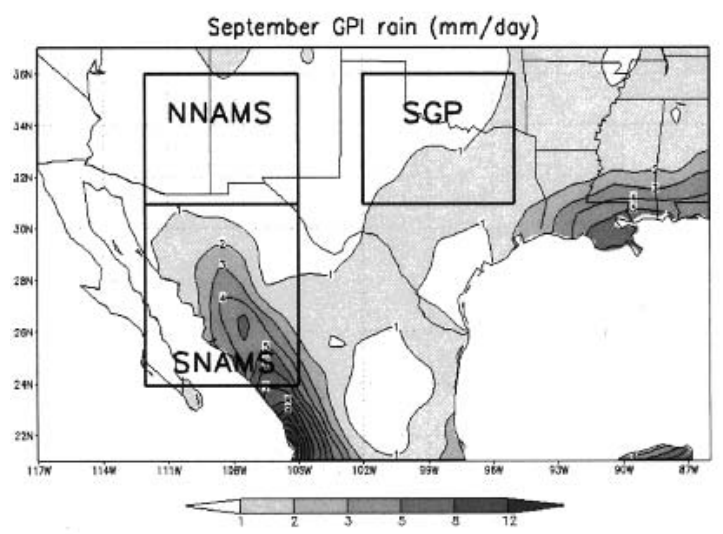

GPI b)

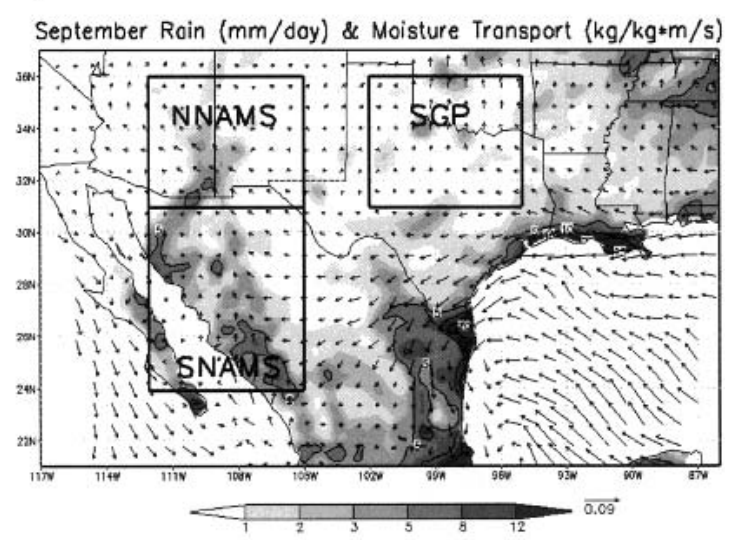

FIX

FIG. 12. (a) Sep precipitation ( $\left.\mathrm{mm} \mathrm{day}{ }^{-1}\right)$ derived from GPI. (b) Sep precipitation (mm day ${ }^{-1}$; shaded) and near-surface (sigma level $=0.995-0.910)$ vector moisture flux $\left(\mathrm{kg} \mathrm{m} \mathrm{kg}^{-1} \mathrm{~s}^{-1}\right)$ in the FIX experiment.

shows the September precipitation $\left(\mathrm{mm} \mathrm{day}^{-1}\right)$ derived from the Geostationary Operational Environmental Satellite (GOES) Precipitation Index (GPI) data (Janowiak and Arkin 1991). The DYN simulation closely features the GPI in the NAMS region (Fig. 6). The FIX experiment exhibits the anomalous precipitation tongue across the NNAMS (Fig. 12b), which is not observed from the GPI measurement.

First, we describe antecedent surface and atmospheric conditions in comparison between the DYN and FIX experiment. As seen in Fig. 8, Fg-precipitation and Fg-EF scatter demonstrates a weak negative feedback at the regional scale and most of the individual points in the DYN - FIX comparison. Although we found that the soil moisture deficit limits transpiration, a positive ET-precipitation feedback is present in the NAMS region. Figure 13a shows the seasonally averaged canopy resistance index (red shaded) from the DYN experiment and mean difference in $\mathrm{Fg}$ between the DYN and FIX experiment (DYN - FIX, in percent;-contour). In the DYN experiment, greater Fg and a significant degree of the canopy resistance are collocated in a western portion of the domain, while the eastern portion of the domain is unrestricted from the canopy resistance. Particularly, canopy resistances in the southern portion of the Baja California, the northwestern portion of the SNAMS, the southern edge of the NNAMS, and central Mexico are greater than 3.5, which minimizes transpiration and EF as examined in section $3 b(4)$. Thus, across these regions, land surface conditions in the DYN experiment are characterized with a small fraction of bare soil and a large fraction of stressed vegetation cover, whereas land surface conditions in the FIX experiment are characterized with a large fraction of bare soil and a small fraction of stressed vegetation cover. As a result, the FIX experiment has greater ET and EF than that in the DYN experiment in the red-shaded regions, such as the SNAMS.

Figure 13b shows the difference in seasonally averaged EF between the DYN and FIX experiments. In the DYN-FIX comparison, the area where greater Fg and severe canopy stress coexist (including the southern portion of the Baja California, the northwestern portion of the SNAMS, the southern edge of the NNAMS, and central Mexico), show the negative anomalies (red shaded) of EF. On the other hand, the areas where canopy resistance is unrestricted from soil moisture deficit (including the southern edge of Mexico and the western portion of SGP), show positive anomalies (blue shaded). Overall, the anomalies of EF between the DYN and FIX experiments are either positively or negatively controlled by a combination of the variability of the $\mathrm{Fg}$ and the degree of canopy stress index.

Similarly, Fig. 13c shows the difference of seasonally averaged (1 June-9 September) precipitation (red-blue shaded) and upper-troposphere pressure (contour) between the DYN and FIX experiment. Negative (positive) anomalies of precipitation are generally coherent to the anomalies of EF, supporting the consistent EFprecipitation relationship as examined in section $3 b(3)$. Some of the areas do not follow this relationship probably due to orographic lifting, the sea breeze (particularly along the coast area), and tropical cyclones. In this study, lower Fg in the FIX experiment enhances precipitation (red shaded) in most of the SNAMS, a southern portion of the NNAMS, and northeastern Mexico. This tendency of the surface energy flux in the FIX experiment enhanced the upper-level (sigma level = $0.125)$ pressure gradient between the southwestern United States and the ocean (Fig. 13c). This indicates that variability of $\mathrm{Fg}$ boundary conditions consistently modulate surface flux and atmospheric circulation 
a)

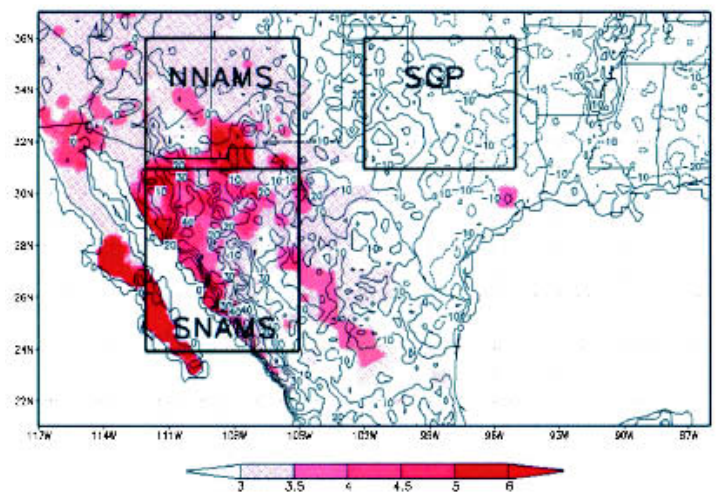

c)

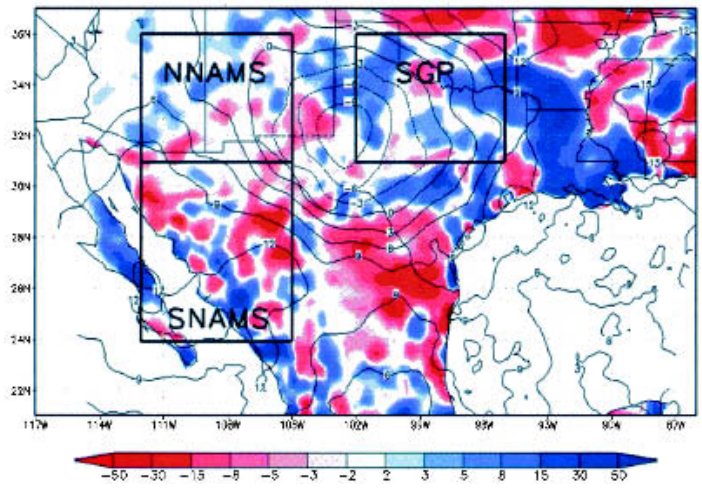

b)

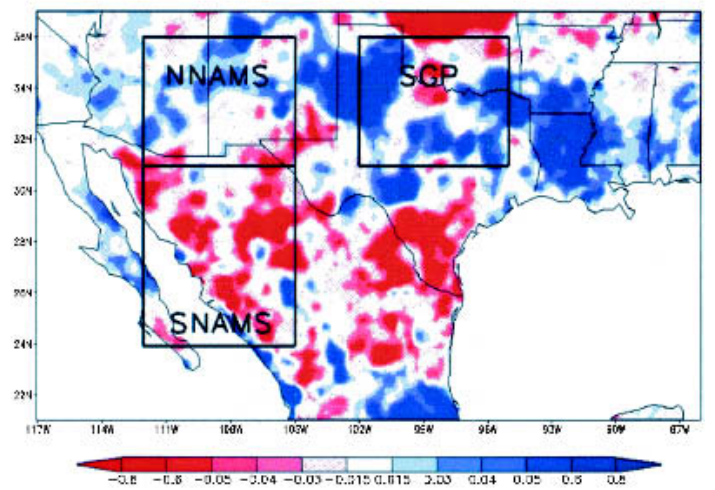

d)

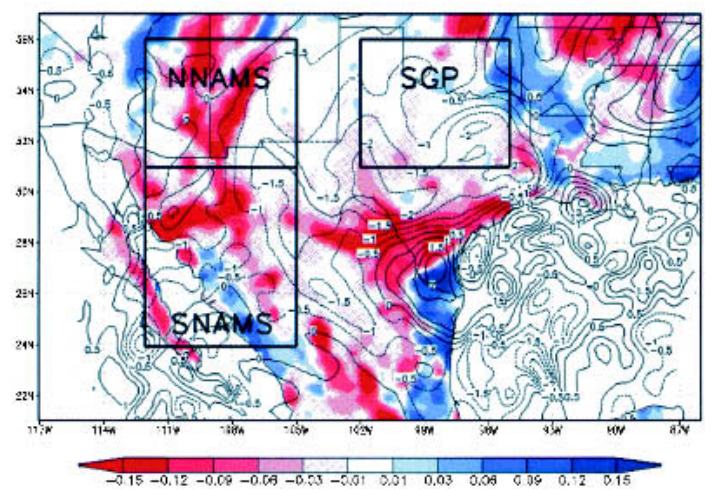

FIG. 13. (a) Seasonally averaged $\log _{10}$ (canopy resistance index; red shaded) and intraseasonal anomalies of Fg (\%; DYN - FIX; contour). (b) Difference of seasonally averaged (1 Jun-9 Sep) EF in DYN - FIX comparison. (c) Difference of seasonally averaged (1 Jun-9 Sep) precipitation ( $\mathrm{mm}$; blue-red shaded) and upper-troposphere (sigma level $=0.125)$ pressure $(\mathrm{mb}$; contour) in DYN - FIX comparison. (d) Difference of surface volumetric soil moisture (blue-red shaded) and total precipitable water ( $\mathrm{cm}$; contour).

throughout the experiment. On 9 September, significant anomalies of soil moisture (red-blue shaded) and total precipitable water (TPW; contour) exist over the domain between the DYN and FIX experiment (Fig. 13d). TPW in the FIX and DYN experiment is 3.17 and $2.69 \mathrm{~cm}$ in the NAMS region, while TPW obtained from the NCEP-NCAR reanalysis is $2.08 \mathrm{~cm}$ in the same region. Surface soil moisture in the FIX experiment is also greater in the NAMS region and Mexico.

On 9 September, two tropical cyclones appeared off the coast of the southern edge of the Baja California and in the Gulf of Mexico in the DYN and the FIX experiment. Figure 14a exhibits 5-day mean rainfall (mm day ${ }^{-1}$; dark shaded) and near-surface moisture flux (vector) after 9 September in the DYN and the FIX experiments. In the DYN experiment, a tropical cyclone proceeds from the northeast Pacific toward the northwest. On the other hand, in the FIX experiment, a tropical cyclone proceeds toward the Gulf of California and interior of the NNAMS, and generates a significant amount of precipitation across the NNAMS. Although it is not directly connected to the precipitation anoma- lies in the NAMS region, a cyclone in the Gulf of Mexico also shows a different track, which results in anomalous precipitation along the coast of the Gulf of Mexico between the DYN and FIX experiment.

Figure $14 \mathrm{~b}$ shows the mean zonal flow averaged over $24^{\circ}-34^{\circ} \mathrm{N}$ during $9-12$ September in the DYN and FIX experiment. There is a strong easterly flow (3 $\mathrm{m} \mathrm{s}^{-1}$ ) in the lower atmospheric level and relatively weak westerly flow in the upper level in the DYN experiment, while there is a weak easterly flow $\left(1 \mathrm{~m} \mathrm{~s}^{-1}\right)$ in the lower atmospheric level and a strong westerly flow in the upper level in the FIX experiment, which steers the tropical cyclone toward the interior of the NNAMS.

Considering that the lateral and surface boundary conditions are identical between three experiments, except for $\mathrm{Fg}$, we can conclude that variability of the $\mathrm{Fg}$ boundary condition affects the route of the tropical cyclones through consistently modulating the land surface energy flux and regional atmospheric circulation. This cyclone-induced precipitation results in the largest sensitivity between the DYN and FIX experiment. 
a)
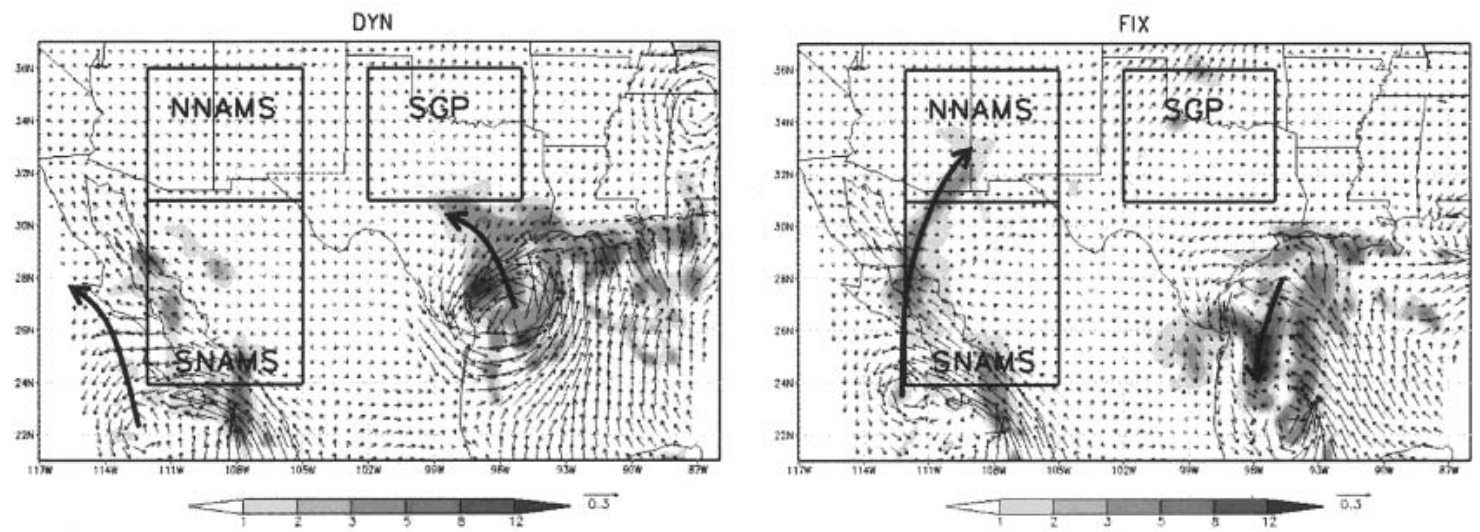

b)
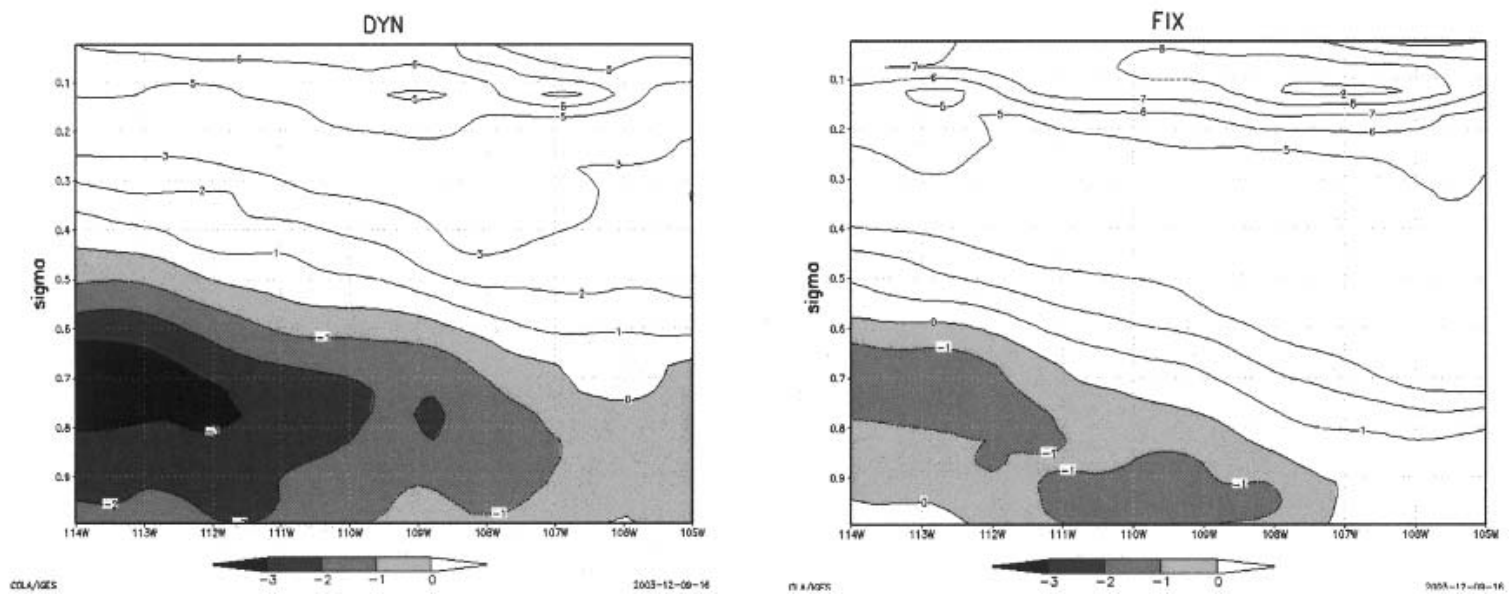

FIG. 14. (a) Five-day mean (9-13 Sep) precipitation $\left(\mathrm{mm} \mathrm{day}^{-1}\right.$; shaded) and near-surface (sigma level $\left.=0.995-0.910\right)$ vector moisture flux $\left(\mathrm{kg} \mathrm{m} \mathrm{kg}^{-1} \mathrm{~s}^{-1}\right)$ on 9 Sep in the DYN experiment and the FIX experiment. Thick arrows show tracks of tropical cyclones. (b) Mean (over $24^{\circ}-34^{\circ} \mathrm{N}$ and 4 days from 9-12 Sep) zonal wind cross section at the sigma level in the DYN and FIX experiment. Easterly flow is shaded in gray.

\section{Summary}

Twenty-year monthly greenness fraction $(\mathrm{Fg})$ data over the North America are derived from GIMMS NDVI. The derived Fg exhibits heterogeneity in time and space. Substantial evolution of Fg exists across the western slope of Sierra Madre Occidental. The variability of the NAMS precipitation is likely to contribute to the wet-/dry-year and intraseasonal vegetation anomalies, indicating the presence of vegetation feedback in the NAMS region. Four-month-long regional climate simulations (MM5-OSU LSM) was used to assess the sensitivity of the seasonal NAMS simulation in 2000 to three different Fg boundary conditions. Three simulation experiments (DYN, FIX, and DIFF) are designed to examine the influence of 1) intraseasonal and 2) wet-/dry-year anomalies of Fg through the change in the surface energy and moisture flux, boundary layer state, and precipitation.
At the regional scale, the influence of $\mathrm{Fg}$ on surface and atmospheric fields is minor or not discernable in the simulations. In particular, wet-/dry-year anomalies of Fg do not influence the regional climate to a distinguishable degree, as determined by comparing the DYN and the DIFF simulations. Intraseasonal anomalies of Fg weakly influence the simulated climate through the season. In particular, fixed $\mathrm{Fg}$ leads to slightly higher precipitation from June to August and a substantial overestimation of precipitation toward the end of the monsoon season. Local correlations within the NAMS regions demonstrate that higher ET leads to higher EF, lower temperature, higher relative humidity in the $\mathrm{BL}$, and precipitation as proposed by Betts and Ball (1998) and Eltahir (1998). Considering the presence of other factors (orographic lifting, sea breeze, and large-scale monsoon circulation) that affect cumulus convection, the EF-precipitation pathway plays a role in the modeling system used here. 
However, higher Fg does not consistently enhance ET and EF across the NAMS region, but instead tends to lower it. Grid-by-grid scatterplots show that negative feedback points exist more than positive feedback points in the intraseasonal comparison (DYN - FIX) and in the NAMS region. The soil moisture deficit across the NAMS region yields high canopy resistance values throughout the monsoon season, minimizing the water flux from soil to the atmosphere via transpiration. This leads to the unexpected response that bare soil evaporation $\left(E_{\mathrm{dir}}\right)$ is more efficient than the sum of the transpiration $\left(E_{t}\right)$, and the evaporation from the canopy interception $\left(E_{c}\right)$ in the NAMS region. We found that, instead of $\mathrm{Fg}$, the primary control on the EF is soil moisture and soil texture in the NAMS region, although this conclusion could be altered with a different combination of initial soil moisture conditions and transpiration parameterization.

The SNAMS and a southern portion of the NNAMS are characterized by a large fraction of bare soil and a small fraction of stressed vegetation in the FIX experiment, and vice versa in the DYN experiment. The FIX experiment, thereby, consistently increases the ET and EF in the SNAMS, enhancing a positive soil moisture feedback. Eventually, the FIX experiment creates positive anomalies of soil moisture in the SNAMS and a stronger upper-level pressure gradient between land and ocean. As a result, the modulated atmospheric circulation in the FIX experiment steers the track of the tropical cyclones that yields a substantial precipitation in the NAMS region. This results in the largest sensitivity between the DYN and FIX experiment through the season.

\section{Constraints on simulating vegetation-atmosphere interactions}

Our work raised a number of constraints on simulating the influence of vegetation cover on climate in the NAMS region.

(i) The parameterization of canopy resistance index at the scale of LSM or mesoscale atmospheric models (here $30 \mathrm{~km} \times 30 \mathrm{~km}$ ) is critical, but difficult to constrain. Although the offline OSU LSM yielded a good estimate of total ET over the tall grassland at the FIFE site (Chen et al. 1996; Chen and Dudhia 2001b), transpiration in the NAMS regions was severely limited by soil moisture throughout the simulations. This is not consistent with plant-level measurements of transpiration in semiarid environments (Yan et al. 2000). Even though soil moisture in the SNAMS becomes higher than that in the SGP, canopy resistance index in the SNAMS is very high throughout the seasons. Thus, we suspect that the vegetationdependent canopy resistance coefficient in the parameterization could be the first-order uncertainty rather than the uncertainty in the initial soil moisture conditions.

(ii) More detailed spatial information on soil type and soil moisture is necessary. FAO's global soil texture map has recently been made available at a finer horizontal scale. A different horizontal resolution of the soil texture map would significantly affect the surface energy flux through controlling $\mathrm{EF}$ at a significant degree. New datasets, which will made available using the Advanced Microwave Scanning Radiometer (AMSR; Njoku et al. 2003) and Variable Infiltration Capacity (VIC) model Land-surface Data Assimilation System (LDAS; Maurer et al. 2002), will provide more complete information on soil moisture and will serve to enhance simulations. Together with vegetation parameters, soil parameters need to be ideally calibrated not only at the single watershed but also every point on the regional scale. A highquality offline land surface modeling platform [Land Information System (LIS); Peters-Lidard et al. 2004], extensive surface observations from a new satellite platform [Moderate Resolution Imaging Spectroradiometer (MODIS) and Land product (MODLAND); Justice and Townshend 2002], and efficient calibration framework [MultiObjective Shuffled Complex Evolution Metropolice (MOSCEM); Vrugt et al. 2003] may play key roles for the regional/global scale LSM calibration in near future.

(iii) Even with the customized combination of the convection and radiation scheme ( $\mathrm{Xu}$ and Small 2002), the MM5-OSU LSM) over-/underestimated the simulated rainfall. A different convection scheme results in a modulation on the hydrometeorological response in the NAMS region (Gochis et al. 2003). Until computational power allows us to implement a cloud-resolving regional climate model for the NAMS, a customization of the convective scheme for the region of complex terrain would minimize the simulation error associated with moist convection (Castro et al. 2002). The use of ensemble techniques will also help to reduce the noise in the RCMs. Note that the lagged average or Monte Carlo ensemble simulation may be ineffective using an RCM, because the use of RCMs cannot accept the fundamental assumption that "a model should be essentially perfect" (Toth and Kalnay 1993). An ensemble of multicumulus schemes may help to improve the techniques for seasonal modeling (Krishnamurti and Sanjay 2003).

Land-atmosphere interaction could play an important role to understand the NAM variability, in conjunction with the influence of SSTs and larger-scale circulation (Bosilovich and Schubert 2002; Higgins et al. 1999; Castro et al. 2001). To date, the NAMS science 
community has not been very successful in simulating the NAMS variability with a RCM. Thus, future investigations should consider the aforementioned uncertain factors for better understanding and predictability of the NAMS.

Acknowledgments. This work has been funded by NAG59233 (University of South Carolina) and NAG59328 (New Mexico Tech) from the NASA Earth Science Enterprise. The authors thank Dr. Diane Wickland, Program Manager at NASA HQ, for her support. The authors thank Dr. Compton Tucker and Ms. Molly Brown for the GIMMS NDVI product, and Mesoscale and Microscale Meterology (MMM) scientists of National Center of Atmospheric Research (NCAR) for MM5-OSU LSM. The first author thanks the Goddard Earth Sciences and Technology (GEST) Center Graduate Student Summer Program (GSSP) that initiated this work under the mentorship of Yogesh Sud in the Climate and Radiation Branch at the NASA GSFC. The authors would like to acknowledge the useful comments from two anonymous reviewers.

\section{APPENDIX}

\section{Evaporation and Transpiration Parameterization}

In this section, we describe the parameterization of evaporation and transpiration in the land surface model. The OSU LSM incorporates the greenness fraction (Fg), vegetation category, and soil types to parameterize surface energy flux. The vegetation category prescribes the albedo, emissivity, minimum stomatal resistance, moisture availability, and thermal inertia. The current version of the MM5-OSU LSM specifies the seasonal albedo in summer and winter. Albedo is a critical variable for calculating surface energy budget, which provides feedback to the climate system (e.g., Sud and Molod 1988). In this study, we modified seasonally prescribed albedo to dynamically change in time and space as a function of $\mathrm{Fg}$ and surface soil moisture by interpolating summer and winter albedo prescribed in USGS land cover data.

For this study ET formulation is critical, because changes in vegetation fraction impact how water in the soil is released to the atmosphere via latent heat flux. A more detailed description can be found in Chen and Dudhia (2001a). Total ET $(E)$ is treated as a sum of three components: evaporation from the bare soil $\left(E_{\mathrm{dir}}\right)$, evaporation of rain trapped on the canopy $\left(E_{c}\right)$, and transpiration from the plant stomata $\left(E_{t}\right)$ :

$$
E=E_{\mathrm{dir}}+E_{c}+E_{t} \text {. }
$$

Evaporation from the bare soil $\left(E_{\text {dir }}\right)$ is computed linearly in a way similar to that of Mahfouf and Noilhan (1991):

$$
E_{\mathrm{dir}}=\left(1-F_{g}\right)\left(\frac{\Theta_{1}-\Theta_{w}}{\Theta_{\mathrm{cap}}-\Theta_{w}}\right) E_{P}
$$

where Fg is the greenness fraction, $\Theta_{1}$ is soil moisture at the topsoil layer, $\Theta_{\text {cap }}$ is soil moisture at the field capacity, $\Theta_{w}$ is soil moisture at the wilting point, and $E_{P}$ is potential Penman-based evaporation (Mahrt and Pan 1984).

Evaporation from the canopy $\left(E_{c}\right)$ is defined as

$$
E_{c}=F_{g} E_{P}\left(\frac{W_{c}}{S}\right)^{0.5}
$$

where $\partial W_{c} / \partial t=F_{g} P-D-E_{c}, W_{c}$ is intercepted canopy water content, $S$ is the maximum canopy capacity $(0.5 \mathrm{~mm}$ is assigned for forest; 0.25 is assigned for shrubs and grass; McCumber and Pielke 1981), $P$ is total precipitation reached on the vegetation, and $D$ is rain through fall from the canopy (Noilhan and Planton 1989).

Transpiration rate is computed based on the potential evaporation $\left(E_{P}\right)$ and is temporally controlled by plant stress $\left(R_{c}\right)$ and intercepted canopy water content $\left(W_{c}\right)$ :

$$
E_{t}=F_{g} E_{P} B_{c}\left[1-\left(\frac{W_{c}}{S}\right)^{0.5}\right]
$$

where $B_{c}=1+\Delta / R_{r} / 1+R_{c} C_{h}+\Delta / R_{r}, C_{h}$ is the surface exchange coefficient for heat and moisture, $\Delta$ is the slope of the saturation specific humidity curve, and $R_{r}$ is a function of the surface air temperature (Ek and Mahrt 1991). Computation of canopy resistance index $\left(R_{c}\right)$ is rather complicated following the formulations of Jacquemin and Noilhan (1990), $R_{c}$ is treated as a function of solar radiation deficit $\left(F_{1}\right)$, vapor pressure deficit $\left(F_{2}\right)$, air temperature deficit $\left(F_{3}\right)$, soil moisture deficit $\left(F_{4}\right)$, minimum stomatal resistance $\left(R_{c \text { min }}\right)$, and leaf area index (LAI):

$$
R_{c}=\frac{R_{c \min }}{F_{1} F_{2} F_{3} F_{4}}
$$$$
F_{1}=\frac{R_{c \text { min }} / R_{c \max }+f}{1+f}, \quad \text { (solar radiation deficit) }
$$

where $f=0.55 \frac{R_{g}}{R_{\mathrm{gl}}} \frac{2}{\mathrm{LAI}}$

$F_{2}=\frac{1}{1+h_{s}\left[q_{s}\left(T_{a}\right)-q_{a}\right]}, \quad$ (vapor pressure deficit)

$F_{3}=1-0.0016\left(T_{\text {ref }}-T_{a}\right)^{2}, \quad$ (air temperature deficit)

$F_{4}=\sum_{i=1}^{3} \frac{\left(\Theta_{i}-\Theta_{w}\right) d_{Z_{i}}}{\left(\Theta_{\text {ref }}-\Theta_{w}\right)\left(d_{Z_{1}}-d_{Z_{2}}\right)}, \quad$ (soil moisture deficit) 
where $q_{s}\left(T_{a}\right)$ is the saturated water vapor mixing ratio at the temperature $\left(T_{a}\right), R_{c \text { max }}$ is the cuticular resistance of the leaves $\left(5000 \mathrm{~s} \mathrm{~m}^{-1}\right)$, and $d_{\mathrm{Zi}}$ is the depth of the specific soil layer.

Among all of the terms, the soil moisture deficit term is important over semiarid regions. Chen et al. (1996) found that the original narrowband of soil moisture between wilting and reference points strongly activate the canopy resistance during the dry period. Chen et al. (1996) incorporated a probability density function of heterogeneous soil moisture to yield ET ( $E_{\mathrm{dir}}$ and $\left.E_{c}\right)$ beyond the wilting point and to reduce the total evaporation when the area-averaged soil moisture is at the reference point, following Wetzel and Chang (1987). In order to minimize computational time, the original wilting and reference soil moisture is simply broadened to relax the ET in the current MM5-OSU LSM as

$$
\begin{aligned}
\Theta_{\text {ref }} & =\Theta_{S}\left[\frac{1}{3}+\frac{2}{3}\left(\frac{5.79 \times 10^{-9}}{K_{S}}\right)^{\frac{1}{2 b+3}}\right], \\
\Theta_{w} & =0.5 \Theta_{S}\left(\frac{200}{\Psi_{S}}\right)^{-\frac{1}{b}},
\end{aligned}
$$

where $\Theta_{S}$ is porosity $\left(\mathrm{m}^{3} \mathrm{~m}^{-3}\right), \Psi_{s}$ is saturation soil suction $(\mathrm{m})$, and $K_{s}$ is hydraulic conductivity $\left(\mathrm{m} \mathrm{s}^{-1}\right)$ at saturation assigned by Cosby et al. (1984). Seasonal offline simulations provide a good agreement between simulated surface heat fluxes and area-averaged observation over the FIFE area (Chen et al. 1996). Chen and Dudhia (2001b) found that the MM5, coupled with the OSU LSM, simulates reasonable soil thermal hydraulic conductivities and the surface energy balance, both of which are strongly affected by the soil moisture changes.

\section{REFERENCES}

Adams, F. K., and A. C. Comrie, 1997: The North American monsoon. Bull. Amer. Meteor. Soc., 78, 2197-2213.

Betts, A. K., and J. J. Ball, 1998: FIFE surface climate and siteaverage dataset 1987-1989. J. Atmos. Sci., 55, 1091-1108.

Bosilovich, M. G., and S. D. Schubert, 2002: Water vapor tracers as diagnostics of the regional hydrologic cycle. J. Hydrometeor., 3, 149-165.

Castro, C. L., T. B. McKee, and R. A. Pielke Sr., 2001: The relationship of the North American monsoon to tropical and North Pacific surface temperatures as revealed by observational analyses. J. Climate, 14, 4449-4473.

- W. W. Y. Cheng, A. B. Beltran, R. A. Pielke Sr., and W. R. Cotton, 2002: The incorporation of the Kain-Fritch cumulus parameterization scheme in RAMS with a terrain-adjusted trigger function. Fifth RAMS User Workshop, Santorini, Greece, ATMET, Inc.

Chen, F., and J. Dudhia, 2001a: Coupling an advanced land surface-hydrology model with the Penn State-NCAR MM5 modeling system. Part I: Model implementation and sensitivity. Mon. Wea. Rev., 129, 569-585.

, and —-, 2001b: Coupling an advanced land surfacehydrology model with the Penn State-NCAR MM5 modeling system. Part III: Preliminary model validation. Mon. Wea. Rev., 129, 587-604.

- and Coauthors, 1996: Modeling of land-surface evaporation by four schemes and comparison with FIFE observations. $J$. Geophys. Res., 101, 7251-7268.

Cosby, B. J., G. M. Hornberger, R. B. Clapp, and T. R. Ginnn, 1984: A statistical exploration of the relationships of soil moisture characteristics to the physical properties of soils. Water Resour. Res., 20, 682-690.

Dickinson, R. E., A. Henderson-Sellers, and P. J. Kennedy, 1993: Biosphere-Atmosphere Transfer Scheme (BATS) version 1e as coupled to the NCAR community climate model. NCAR Tech. Note NCAR/TN-387+STR, $72 \mathrm{pp}$.

Dudhia, J., 1989: Numerical study of convection observed during the Winter Monsoon Experiment using a mesoscale twodimensional model. J. Atmos. Sci., 46, 3077-3107.

Eastman, J. L., M. B. Coughenour, and R. A. Pielke, 2001: The effects of $\mathrm{CO}_{2}$ and landscape change using a coupled plant and meteorological model. Global Change Biol., 7, 797-815.

Ek, M., and L. Mahrt, 1991: OSU 1-D PBL model user's guide. Department of Atmospheric Sciences, Oregon State University, 120 pp.

Eltahir, E., 1998: A soil moisture-rainfall feedback mechanism. 1. Theory and observations. Water Resour. Res., 34, 765-776.

ERDAS, 1994: ERDAS Field Guide. ERDAS, Inc., 628 pp.

Giorgi, F., and L. O. Mearns, 1999: Introduction to special section: Regional climate modeling revisited. J. Geophys. Res., 104, 6335-6352.

Gochis, D. J., W. J. Shuttleworth, and Z.-L. Yang, 2002: Sensitivity of the modeled North American monsoon regional climate to convective parameterization. Mon. Wea. Rev., 130, $1282-1298$.

,-- , and - , 2003: Hydrometeorological response of the modeled North American monsoon to convective parameterization. J. Hydrometeor., 4, 235-250.

Grell, G., 1993: Prognostic evaluation of assumptions used by cumulus parameterization. Mon. Wea. Rev., 121, 764-787.

— - J. Dudhia, and D. R. Stauffer, 1994: A description of the fifth generation Penn State/NCAR mesoscale model (MM5). NCAR Tech. Note NCAR/TN-380+STR, 138 pp.

Gutman, G., and A. Ignatov, 1998: The derivation of green vegetation fraction from NOAA/AVHRR data for use in numerical weather prediction models. Int. J. Remote Sens., 19, 1533-1543.

Gutzler, D., and J. Preston, 1997: Evidence for a relationship between spring snow cover in North American and summer rainfall in New Mexico. Geophys. Res. Lett., 24, 2207-2210.

Higgins, R. W., Y. Yao, and J. Wang, 1997: Influence of the North American monsoon system on the United States summer precipitation regime. J. Climate, 10, 2600-2622.

_, Y. Chen, and A. V. Douglas, 1999: Interannual variability of the North American warm season precipitation regime. $J$. Climate, 12, 653-680.

Hong, S. Y., and H. L. Pan, 1996: Nonlocal boundary layer vertical diffusion in a medium-range forecast model. Mon. Wea. Rev., 124, 2322-2339.

Jacquemin, B., and J. Noilhan, 1990: Sensitivity study and validation of a land surface parameterization using the HAPEXMOBILHY data set. Bound.-Layer Meteor., 52, 93-134.

Janowiak, J. E., and P. A. Arkin, 1991: Rainfall variations in the Tropics during 1986-1989, as estimated from observations of cloud-top temperatures. J. Geophys. Res., 96, 3359-3373.

Justice, C. O., and J. Townshend, 2002: Special issue on the Moderate Resolution Imaging Spectroradiometer (MODIS): A new generation of land surface monitoring. Remote Sens. Environ., 83, 1-2.

Kalnay, E., and Coauthors, 1996: The NCEP/NCAR 40-Year Reanalysis Project. Bull. Amer. Meteor. Soc., 77, 437-471.

Krishnamurti, T. N., and J. Sanjay, 2003: A new approach to the cumulus parameterization issue. Tellus, 55A, 275-300. 
Lo, F., and C. P. Martyn, 2002: Relationships between spring snow mass and summer precipitation in the southwestern United States associated with the North American monsoon system. J. Climate, 15, 1378-1385.

Mahfouf, J. F., and J. Noilhan, 1991: Comparative study of various formulations from bare soil using in situ data. J. Appl. Meteor., 30, 1354-1365.

Mahrt, L., and H. L. Pan, 1984: A two-layer model of soil hydrology. Bound.-Layer Meteor., 29, 1-20.

Matsui, T., V. Lakshmi, and E. E. Small, 2003: Links between snow cover, surface skin temperature, and rainfall variability in the North American monsoon system. J. Climate, 16, 18211829.

Maurer, E. P., A. W. Wood, J. C. Adam, and D. P. Lettenmaier, 2002: A long-term hydrologically based dataset of land surface fluxes and states for the conterminous United States. $J$. Climate, 15, 3237-3251.

McCumber, M. C., and R. A. Pielke, 1981: Simulation of the effects of surface fluxes of heat and moisture in a mesoscale numerical model soil layer. J. Geophys. Res., 86, 9929-9938.

Miller, D. A., and R. A. White, 1998: A conterminous United States multi-layer soil characteristics data set for regional climate and hydrology modeling. Earth Interactions, 2. [Available online at http://EarthInteractions.org.]

Mlawer, E. J., S. J. Taubman, P. D. Brown, M. J. Iacono, and S. A. Clough, 1997: Radiative transfer for inhomogeneous atmosphere: RRTM, a validated correlated-k model for the longwave. J. Geophys. Res., 102 (D14), $16663-16682$.

Njoku, E. G., T. L. Jackson, V. Lakshmi, T. Chan, and S. V. Nghiem, 2003: Soil moisture retrieval from AMSR-E. IEEE Trans. Geosci. Remote Sens., 41, 215-229.

Noilhan, J., and S. Planton, 1989: A simple parameterization of land surface processes for meteorological models. Mon. Wea. Rev., 117, 536-549.

Peters-Lidard, C. D., S. Kumar, Y. Tian, J. L. Eastman, and P. Houser, 2004: Global urban-scale land-atmosphere modeling with the land information system. Preprints, Symp. on Planning, Nowcasting, and Forecasting in the Urban Zone, Seattle, WA, Amer. Meteor. Soc., CD-ROM.

Pielke, R. A., Sr., 2001: Influence of the spatial distribution of vegetation and soils on the prediction of cumulus convective rainfall. Rev. Geophys., 39, 151-177.

Price, J., 1993: Estimating leaf area index from satellite data. IEEE Trans. Geosci. Remote Sens., 31, 727-734.

Reynolds, R. W., and T. M. Smith, 1994: Improved global sea surface temperature analyses using optimum interpolation. $J$. Climate, 7, 929-948.

Segal, M., R. Avissar, M. C. McCumber, and R. A. Pielke, 1988: Evaluation of vegetation effects on the generation and modi- fication of mesoscale circulations. J. Atmos. Sci., 45, 2268 2292.

Sellers, P. J., S. O. Los, C. J. Tucker, C. O. Justice, D. A. Dazlich, D. J. Collatz, and D. A. Randall, 1996: A revised land surface parameterization (SiB2) for atmospheric GCMs. Part II: The generation of global fields of terrestrial biophysical parameters from satellite data. J. Climate, 9, 706-737.

Small, E., 2001: The influence of soil moisture anomalies on variability of the North American monsoon system. Geophys. Res. Lett., 28, 139-142.

- and S. Kurc, 2003: Tight coupling between soil moisture and the surface radiation budget in semiarid environments: Implications for land-atmosphere interaction. Water Resour. Res., 39, 1278, doi:10.1029/2002WR001297.

Sud, Y. C., and A. Molod, 1988: A GCM simulation study of the influence of Saharan evapotranspiration and surface-albedo anomalies on July circulation and rainfall. Mon. Wea. Rev., 116, 2388-2400

- W. C. Chao, and G. K. Walker, 1993: Dependence of rainfall on vegetation: Theoretical considerations, simulation experiments, observations, and inferences from simulated atmospheric soundings. J. Arid Environ., 25, 5-18.

Swetnam, T. W., and J. L. Betancourt, 1998: Mesoscale disturbance and ecological response to decadal climatic variability in the American Southwest. J. Climate, 11, 3128-3147.

Toth, Z., and E. Kalnay, 1993: Ensemble forecasting at NMC: The generation of perturbations. Bull. Amer. Meteor. Soc., 74, 2317-2330.

Trenberth, K. E., and G. W. Branstator, 1996: Physical processes involved in the 1988 drought and 1993 floods in North America. J. Climate, 9, 1288-1298.

Vrugt, J. A., H. V. Gupta, L. A. Bastidas, W. Bouten, and S Sorooshian, 2003: Effective and efficient algorithm for multiobjective optimization of hydrologic models. Water Resour. Res., 39, 1214, doi:10.1029/2002WR001746.

Wetzel, P., and J. T. Chang, 1987: Concerning the relationship between evapotranspiration and soil moisture. J. Climate Appl. Meteor., 26, 18-27.

Xu, J. J., and E. E. Small, 2002: Simulating summertime rainfall variability in the North American monsoon region: The influence of convection and radiation parameterizations. $J$. Geophys. Res., 107, 4727, doi:10.1029/2001JD002047.

Yan, S., C. Wan, R. E. Sosebee, D. B. Wester, E. B. Fish, and R. E. Zartman, 2000: Responses of photosynthesis and water relations to rainfall in the desert shrub creosote bush (Larrea tridentata) as influenced by municipal biosolids. J. Arid Environ., 46, 397-412.

Zobler, L., 1986: A world soil file for global climate modeling. NASA Tech. Memo. 87802, 33 pp. 